\title{
Simulating gas-aerosol-cirrus interactions: Process-oriented microphysical model and applications
}

\author{
B. Kärcher \\ Deutsches Zentrum für Luft- und Raumfahrt (DLR), Institut für Physik der Atmosphäre (IPA), Oberpfaffenhofen, Germany
}

Received: 13 June 2003 - Published in Atmos. Chem. Phys. Discuss.: 29 July 2003

Revised: 29 September 2003 - Accepted: 3 October 2003 - Published: 7 October 2003

\begin{abstract}
This work describes a process-oriented, microphysical-chemical model to simulate the formation and evolution of aerosols and ice crystals under the conditions prevailing in the upper troposphere and lower stratosphere. The model can be run as a box model or along atmospheric trajectories, and considers mixing, gas phase chemistry of aerosol precursors, binary homogeneous aerosol nucleation, homogeneous and heterogeneous ice nucleation, coagulation, condensation and dissolution, gas retention during particle freezing, gas trapping in growing ice crystals, and reverse processes. Chemical equations are solved iteratively using a second order implicit integration method. Gas-particle interactions and coagulation are treated over various size structures, with fully mass conserving and non-iterative numerical solution schemes. Particle types include quinternary aqueous solutions composed of $\mathrm{H}_{2} \mathrm{SO}_{4}, \mathrm{HNO}_{3}, \mathrm{HCl}$, and $\mathrm{HBr}$ with and without insoluble components, insoluble aerosol particles, and spherical or columnar ice crystals deriving from each aerosol type separately. Three case studies are discussed in detail to demonstrate the potential of the model to simulate real atmospheric processes and to highlight current research topics concerning aerosol and cirrus formation near the tropopause. Emphasis is placed on how the formation of cirrus clouds and the scavenging of nitric acid in cirrus depends on small-scale temperature fluctuations and the presence of efficient ice nuclei in the tropopause region, corroborating and partly extending the findings of previous studies.
\end{abstract}

\section{Introduction}

Aerosol dynamics and aerosol-cloud interactions involve fundamental physical and chemical processes that produce, transform, and remove particles in the atmosphere. The need

Correspondence to: B. Kärcher

(bernd.kaercher@dlr.de) to study such phenomena experimentally is clearly recognized, and the use of numerical and theoretical simulation tools is of similar importance.

Field, laboratory, and remote sensing measurements can be interpreted by means of modeling. The interpretation of measurements with models can close gaps by describing mechanisms that are not accessible during the observations. Further, modeling may lead to important generalizations by allowing to predict how the measured objects would behave in situations different from those that were actually present during the observations. This can be accomplished with process-oriented models, covering many individual physical and chemical processes in great detail.

Besides this process-oriented application, models can be used as prognostic tools employed in support of planning field measurements or in situations not covered by observations at all. This becomes especially relevant in climate modeling, where the evolution of the global atmosphere needs to be predicted over many decades. Large-scale models of the atmosphere must operate with relatively coarse temporal and spatial resolutions due primarily to their large computational demands and storage requirements.

In conjunction with theoretical considerations, process models can serve yet another purpose. They may help unravel the controlling mechanisms of complex phenomena. Eventually, this may lead to the development of physicallybased parameterization schemes that can be used to handle fundamental processes acting on time scales and spatial scales not resolved by large-scale models.

In the present documentation, a process-oriented, microphysical-chemical model, the Advanced Particle Simulation Code (APSC) is described in detail. The APSC simulates the formation and evolution of aerosol particles and ice crystals under the conditions prevailing in the upper troposphere and lower stratosphere (hereafter referred to as the UTLS region). 
Investigating aerosols and clouds in the UTLS region is an area of active research, spanning from ultrathin cirrus clouds in the tropical tropopause region (Peter et al., 2003) via new aerosol and ice particle formation at the midlatitude tropopause (e.g., Kärcher and Solomon, 1999; de Reus et al., 2000) to unusually large nitric acid trihydrate particles in the lower stratosphere in polar winter (Fahey et al., 2001). This is documented by a variety of projects supported by Stratospheric Processes and Their Role in Climate activities (SPARC, 2003) and by the International Global Atmospheric Chemistry Project within various subprograms (IGAC, 2003). This research area was, and still is, a key element in projects studying the impact of aviation upon the atmosphere, in the United States of America (Friedl, 1997; Kawa, 1999) and in Europe (CORSAIRE, 2003).

The main motivation to set up the APSC was driven by the need to provide a modeling tool suitable to study in detail the behavior of particles in the UTLS region. Because cirrus clouds frequently form at the low temperatures and still relatively high water vapor mixing ratios prevailing in this region, a key requirement was that the code should treat ice nucleation and describe the interaction between trace gases, liquid, mixed, or solid aerosol particles, and ice crystals.

In several aspects, the APSC is similar to other nonequilibrium codes describing the behavior of stratospheric aerosols and the formation of polar stratospheric clouds although only few such models have been well documented (Turco et al., 1979; Toon et al., 1988; Meilinger, 1995; Larsen, 2000; Lowe et al., 2003). In addition, the APSC contains features such as coagulation and nucleation of aerosol particles that are typical processes in codes simulating the tropospheric aerosol (Binkowski and Shankar, 1995; Jacobson, 1999; de Reus et al., 2000; Pirjola and Kulmala, 2001). Cirrus parcel models are also available (see references listed in Lin et al. (2002)), but often these models only treat the ice initiation phase and therefore do not cover the whole set of aerosol dynamical processes.

This document is organized as follows. Section 2 discusses general features of the APSC, including the treatment of dynamics, gas phase chemistry, and particle representation and chemical composition. Section 3 provides details of the microphysical core processes that are covered by the APSC, including numerical solution schemes employed in the code, and dicusses illustrative case studies addressing aerosol nucleation, coagulation, and growth and ice formation and growth. A brief summary of possible model extensions and the conclusions are given in Sects. 4 and 5, respectively. A notation section provides guidance through the equations presented in this work and an appendix discusses important parameters related to the microphysics of ice crystals. Some relationships used here are based on the monograph by Pruppacher and Klett (1997) to which we refer for an in-depth discussion of aerosol and cloud microphysics.

The case studies presented in Sect. 3 are applications of the model demonstrating its potential to simulate real atmo- spheric processes. Comparisons of APSC results to analytical solutions of selected problems have been carried out, but such technical aspects are not documented here. Specifically, the APSC has been tested against analytical solutions of the mixing equations with a mixing rate decaying inversely proportional with time; the condensation equations in the diffusion limit; and the coagulation equations assuming constant coagulation rate coefficients. In addition, for the fully coupled system of equations treated in the APSC, plausibility checks based on time scales for individual processes have been performed and the conservation of the total number of each molecular species and the total number of particles in aerosol/ice phase transitions is checked after every time step.

\section{General Aspects}

\subsection{Dynamics}

The APSC can be employed in two basic modes: the box (or parcel) mode and the trajectory mode. Usually, the thermodynamic variables air temperature $T$ and air pressure $p$ are connected via the adiabatic law, but $p$ and $T$ may vary nonadiabatically to account for diabatic or mixing processes. Under UTLS conditions, it is a very good approximation to make no difference between air and particle temperatures.

In the box mode, we envisage a parcel of air that undergoes prescribed changes of $T$ and $p$. The box may be fixed at a given spatial location, or may represent an actual air parcel undergoing vertical (rising and sinking) motions. The box may have closed boundaries, but cross-boundary fluxes of trace gases, particles, or heat may be allowed, for instance, to simulate exchange of vapor with solid walls in an aerosol chamber or entrainment and detrainment of air in the vicinity of clouds.

In the trajectory mode, the air parcel follows the thermodynamic evolution along an atmospheric trajectory moving along isentropic surfaces or driven by three-dimensional wind fields. Calculations along a large number of domainfilling trajectories may be carried out to cover large spatial regions for an extended period of time. Mixing effects, for instance caused by turbulent entrainment of air in dispersing plumes, may or may not be allowed.

\subsection{Gas phase chemistry}

A simple gas phase chemistry is included in the APSC to predict the chemical production of nucleating and condensing gases. As sulfuric acid $\left(\mathrm{H}_{2} \mathrm{SO}_{4}\right)$ is known to be an extremely efficient aerosol-producing agent in the free troposphere and lower stratosphere owing to its exceedingly low equilibrium vapor pressure, the gas phase chemical module treats the reactions between $\mathrm{SO}_{2}$, its oxidation products $\mathrm{SO}_{3}$, $\mathrm{HSO}_{3}, \mathrm{H}_{2} \mathrm{SO}_{4}$, and the oxidants $\mathrm{OH}, \mathrm{HO}_{2}, \mathrm{O}_{2}$ (Stockwell and Calvert, 1983), using an updated rate coefficient for the 
reaction of $\mathrm{SO}_{3}$ with water molecules to form $\mathrm{H}_{2} \mathrm{SO}_{4}$ (Reiner and Arnold, 1993).

Chemical kinetics is solved using a second order implicit hybrid integration method for stiff systems (Oran and Boris, 1987). The hybrid method consists of an iterated predictormulti corrector algorithm which classifies the chemical equations as non-stiff or stiff based on a time step to chemical relaxation time ratio for each species. The non-stiff and stiff equations are integrated using an Euler formula and an asymptotic expansion formula, respectively. The corrector equations are iterated until convergence is achieved.

\subsection{Particle representation}

Aerosol particles and ice crystals are discretized over the size coordinate instead of tracking the microphysical evolution of single particles. The latter approach becomes cumbersome in the presence of phase transitions or coagulation, but may yield accurate results when these processes are absent. We use the particle radius $r$ as the size coordinate, which is appropriate for liquid aerosol droplets that have a spherical shape. For non-spherical particles, such as black carbon soot, mineral dust, and ice crystals, $r$ may be interpreted as the radius of a volume-equivalent sphere.

Particle radii are discretized into bins. As a large diameter range from $\sim 1 \mathrm{~nm}$ for the smallest aerosol particles to $\sim 1000 \mu \mathrm{m}$ for the largest ice crystals must be covered, bin widths increase progressively from small to large radii according to the frequently used volume-ratio size distribution (Turco et al., 1979). The bin volume represents the average volume $\mathcal{V}$ of one particle in a certain size bin. Other parameters are the number density $n$ of particles in a size bin per unit volume of air, their surface area density $A$, and their volume density $V$. Dividing the latter three parameters by the bin width (particle mass contained in a bin) allows size (mass) distributions of $n, A$, and $V$ to be calculated.

There are three options (Jacobson, 1999) to represent the discretized particle properties in the APSC. In the quasistationary size structure (grid), the particles grow to their exact sizes during one time step, but the adjusted volumes are fitted back onto a fixed grid at each step in a numberand volume-conserving manner. In the moving-center structure, the size-bin edges are fixed, but the size-bin centers may change. The difference to the quasi-stationary size structure is that all particles are moved to another bin when crossing the respective bin edge instead of fractionating particle properties among two or more bins. In this way, numerical diffusion is greatly reduced. In the hybrid structure, involatile core material (e.g., soot, dust) is treated over a quasistationary grid while during condensation of volatile material (e.g., water vapor, $\mathrm{H}_{2} \mathrm{O}$, or nitric acid, $\mathrm{HNO}_{3}$ ) particles are allowed to grow to their exact sizes. Thus the particles are not moved to other bins during the growth of volatile species, eliminating numerical diffusion. If nonvolatile mate- rial condenses or nucleates (e.g., $\mathrm{H}_{2} \mathrm{SO}_{4}$ or ammonia, $\mathrm{NH}_{3}$ ), its growth is treated separately over the quasi-stationary grid.

One way to model the transformation of aerosols into ice particles is to use the moving-center size structure (Haag et al., 2003a). In the moving-center and quasi-stationary grid, information about the initial aerosol core size of a frozen particle is lost, so that the aerosol size distribution may not be accurately reproduced when the ice particles evaporate. In the hybrid structure, sequential freezing of aerosol particles with a given core mass may result in unrealistic averaging of the total size of ice particles with the same core mass. To avoid this problem, partial freezing of particles in a given bin is not allowed when using the hybrid grid. Instead, all aerosol particles with a given core mass are transformed into ice when the parameter $j_{f} \Delta t=1$, where $j_{f}$ is the freezing rate and $\Delta t$ is the model time step. With this correction, the hybrid size structure is able to reproduce exactly the aerosol distribution after the ice evaporates, but the number densities of ice crystals calculated with this method typically differ by a factor of two or so compared to a calculation that allows partial freezing of particles in a given bin, such as with the moving-center or quasi-stationary grid.

\subsection{Chemical composition of particles}

The APSC results described here were obtained by assuming that liquid aerosol particles are composed of either $\mathrm{H}_{2} \mathrm{O}$ and $\mathrm{H}_{2} \mathrm{SO}_{4}$ (binary mixture), or of $\mathrm{H}_{2} \mathrm{O}, \mathrm{H}_{2} \mathrm{SO}_{4}$, and $\mathrm{HNO}_{3}$ (supercooled ternary solutions, STS). These particle types are believed to be important components of the UTLS aerosol and are the main constituents of liquid type-I polar stratospheric clouds (PSCs). The binary mixture is known to form in the free troposphere and UTLS region by binary homogeneous nucleation, but significant uncertainties remain about tropospheric aerosol nucleation mechanisms. Particulate organic matter is known to exist in upper tropospheric aerosol particles (Murphy et al., 1998), but is not considered here because thermodynamic information to calculate the gasaerosol partitioning is not available.

For applications related to low temperature $(<205 \mathrm{~K})$ stratospheric chemistry, it may be necessary to include $\mathrm{HCl}$ and $\mathrm{HBr}$ to simulate the behavior of the STS particles. These species have been implemented in the main version of the APSC. Their dissolutional growth is treated similar to that of $\mathrm{H}_{2} \mathrm{O}$ and $\mathrm{HNO}_{3}$, as described in Sect. 3.3. Further, there exists an option to include an arbitrary number of insoluble core species to form an internally mixed (liquid/solid) aerosol. The cores could, for instance, represent sites for binary heterogeneous nucleation or could act as heterogeneous ice nuclei (IN). An adsorption equilibrium of $\mathrm{H}_{2} \mathrm{O}$ can be invoked to treat the wetting of the core surfaces as a function of relative humidity. The aerosol particles may undergo homogeneous or heterogeneous freezing to form one type of ice particles containg the same types of chemical species and core material as the internally mixed aerosol. 
A second code version exists, the APSCm, where liquid aerosol particles are treated over the hybrid-size structure and ice particles are treated either over the movingcenter or quasi-stationary grid. In the APSC $m$, the particle scheme is extended to include liquid aerosol particles as described above along with an arbitrary number of solid particles present as external mixtures. Each of these particles may act as IN and form ice crystals on their own, hence, the number of different ice crystal types is equal to the number of different aerosol particle types. Applications of the APSCm are presented in Sect. 3.5.

\subsection{Other features}

The dynamical, chemical, and microphysical (condensation, dissolution, coagulation, binary nucleation, freezing) processes are solved by means of operator splitting using a constant time step $\Delta t$ (except the chemistry solver that subcycles the APSC time step) to maintain a modular code structure. Time steps are chosen such that the results do not change upon variations of $\Delta t$. The calculation of phase transitions (see Sect. 3.2) usually requires the smallest time steps to be taken. A typical time step used in freezing calculations is $\Delta t[\mathrm{~s}]=5 / U\left[\mathrm{~cm} \mathrm{~s}^{-1}\right]$, where $U$ is the peak updraft speed.

In the APSC, the liquid aerosol particles can be assumed to be in equilibrium with ambient $\mathrm{H}_{2} \mathrm{O}$ below a prescribed value for the relative humidity. An equation determining the equilibrium mass of $\mathrm{H}_{2} \mathrm{O}$ in particles is solved iteratively for each size bin as a function of $T$ and the mass concentrations of other soluble components. This option is useful when the relative humidity falls below about $40 \%$, permitting relatively large time steps to be taken; when treating this process kinetically, very small time steps must be used in order to resolve the rapid uptake of $\mathrm{H}_{2} \mathrm{O}$ on small $(<0.1 \mu \mathrm{m})$ aerosol particles accurately.

Finally, there is an option to calculate the optical properties of liquid aerosol particles and (spherical) ice crystals with Mie routines for homogeneous and coated spheres (Wiscombe, 1980; Toon and Ackerman, 1981). A brief summary of possible extensions of the APSC is given in Sect. 4.

\section{Microphysics}

For each basic model equation listed in Sects.3.1-3.5 the corresponding solution method is briefly discussed in Sect. 3.6.

\subsection{Overall mass balance, pressure changes, and mixing}

Microphysical processes do not alter the total number of molecules of a given species, but partition molecules between gas and particle phases, whereby - at fixed temper- ature and pressure - the total number density $n_{\mathrm{t}, l}$ of type- $l$ molecules is a conserved quantity:

$n_{\mathrm{t}, l}=n_{l}+\sum_{k, j} c_{l, k, j}$

where $n_{l}$ is the gas phase number density of type- $l$ molecules, $c_{l, k}$ is the number density of type- $l$ molecules per unit volume of air present in type- $k$ particles, the sum over $k$ runs over all particles types and the sum $j$ runs over all particle size bins.

Of course, number densities may change due to pressure variations or mixing effects. Using the ideal gas law, the variation of $n$ (or $c$ ) reads

$\frac{d n}{d t}=\left(\frac{1}{p} \frac{d p}{d t}-\frac{1}{T} \frac{d T}{d t}\right) n=\frac{\gamma-1}{T} \frac{d T}{d t} n, \quad \gamma=3.5$,

where we have used the adiabatic law $p \propto T^{\gamma}$ to derive the last equation. Introducing the volume mixing ratio $\chi$, being equal to $n$ or $c$ divided by the total number density of air molecules, the rate of change of $\chi$ due to mixing can be cast into the form

$\frac{d \chi}{d t}=-\omega\left(\chi-\chi_{\mathrm{amb}}\right)$,

with $\chi_{\text {amb }}$ denoting the mixing ratio in ambient air (outside the mixing region). Here, $\omega$ is the mixing rate that can be defined as a relative rate of change of air mass between the mixing region and the ambient air, or as a relative rate of change of a plume cross-sectional area, depending on the application. A similar equation can be formulated for the temperature $T$.

\subsection{Phase transitions}

Phase transitions considered in the APSC are binary homogeneous nucleation and freezing of aerosol particles to form ice crystals. (A binary heterogeneous nucleation scheme is implemented but not discussed here.)

\section{Binary homogeneous nucleation}

Nucleation rate coefficients $J$ for $\mathrm{H}_{2} \mathrm{SO}_{4} / \mathrm{H}_{2} \mathrm{O}$ particles per unit volume of air per unit time are taken from Vehkamäki etal. (2002), who provide a parameterization based on results from the classical theory of nucleation. The nucleation rate coefficients can be employed to simulate particle formation at the low temperatures prevailing in the UTLS region. We solve the following equations for the gas phase number densities $n_{l}$, the aerosol-phase number densities $c_{l, \mathrm{a}}$ and the aerosol particle number densities $n_{\mathrm{a}}$ :

$\frac{d n_{l}}{d t}=-J \mathcal{N}_{l}, \quad \frac{d c_{l, \mathrm{a}}}{d t}=J \mathcal{N}_{l}, \quad \frac{d n_{\mathrm{a}}}{d t}=J$,

for $\mathrm{H}_{2} \mathrm{SO}_{4}\left(l=\right.$ sa) and $\mathrm{H}_{2} \mathrm{O}(l=w v)$, where $\mathcal{N}_{l}$ denotes the number of type- $l$ molecules in the critical germ. 
This number follows from the parameterization along with the critical germ radius used to decide into which size bins the new aerosol particles nucleate. Once formed, the $\mathrm{H}_{2} \mathrm{SO}_{4} / \mathrm{H}_{2} \mathrm{O}$ particles stay in the UTLS region as temperatures are too low to evaporate the $\mathrm{H}_{2} \mathrm{SO}_{4}$ molecules.

It is not known how accurate the values of $J$ from the parameterization actually are, even they are based on a sophisticated treatment of the classical theory of binary nucleation. Owing to the relatively low surface area densities of aerosols near the tropopause $\left(<10 \mu \mathrm{m}^{2} \mathrm{~cm}^{-3}\right.$, see Kärcher and Solomon (1999)), the aerosol precursor $\mathrm{H}_{2} \mathrm{SO}_{4}$ can reach relatively high concentrations and binary nucleation occurs preferentially in a burst. In nucleation bursts, however, the number of new aerosol particles formed is rather insensitive to details of $J$ (Clement and Ford, 1999). We discuss one case of a nucleating aerosol in Sect. 3.4.

\section{Homogeneous freezing and gas retention}

Rate coefficents $J_{f}$ for homogeneous freezing nucleation per unit aerosol volume per unit time are taken from Koop et al. (2000). In this parameterization, based on a wealth of laboratory data, $J_{f}$ is a function of $T$ and the size-dependent water activity $a_{w}$ in the supercooled aerosol particles. The water activity is defined as the equilibrium vapor pressure of $\mathrm{H}_{2} \mathrm{O}$ over the solution divided by the equilibrium vapor pressure of $\mathrm{H}_{2} \mathrm{O}$ over pure water. It depends on the actual mass fractions of chemical species in the particles which may not be in thermodynamic equilibrium (see Sect. 3.3). Assuming rapid freezing of liquid water in the aerosol volume, the following equations are solved for each type of aerosol particles of radius $r$ :

$$
\frac{d n_{\mathrm{a}}}{d t}=-j_{f} n_{\mathrm{a}}, \quad \frac{d n_{\mathrm{i}}}{d t}=j_{f} n_{\mathrm{a}}, \quad j_{f}=4 \pi r^{3} / 3 \cdot J_{f} .
$$

In addition, particulate species concentrations are moved from the aerosol to the ice particle and gas phase during freezing, i.e.,

$$
\begin{aligned}
\frac{d c_{l, \mathrm{a}}}{d t} & =-j_{f} c_{l, \mathrm{a}} \\
\frac{d c_{l, \mathrm{i}}}{d t} & =j_{f} c_{l, \mathrm{a}} R_{l} \\
\frac{d n_{l}}{d t} & =j_{f} c_{l, \mathrm{a}}\left(1-R_{l}\right) .
\end{aligned}
$$

The retention coefficient $R_{l}$ is defined as the fraction of a gas entrapped in a freezing particle. Setting $R_{l}=1$ assumes that all the dissolved type- $l$ molecules are retained in ice particles upon freezing. This is assumed for $\mathrm{H}_{2} \mathrm{O}$, the strong acid $\mathrm{H}_{2} \mathrm{SO}_{4}$, and all types of insoluble nuclei, but not for $\mathrm{HNO}_{3}$, where $R_{l}$ is treated as a free parameter. In general, $R_{l}$ depends on $T$, the cooling history, and on the nature of the ice surface and the adsorbing molecules. The values of $R_{l}$ for $\mathrm{HNO}_{3}$ and other soluble species are not tightly constrained by available experimental data (see Yin et al.
(2002) and references therein), and a physical representation of retention under UTLS conditions is lacking.

\section{Heterogeneous freezing}

Arguments have been presented that immersion freezing is perhaps the most likely pathway for heterogeneous freezing in the UTLS region (Kärcher and Lohmann, 2003). We compute rate coefficients for immersion freezing of an insoluble IN (core) particle with a radius $r_{c}$ immersed in a liquid aerosol of radius $r>r_{c}$ using the shifted activity method proposed by Kärcher and Lohmann (2003). In this method, the above homogeneous freezing rate coefficient is calculated with a modified activity, $a_{w}+\delta a_{w}$. A critical heterogeneous freezing threshold is prescribed and used to compute the shift $\delta a_{w}$ such that the desired heterogeneous freezing occurs around the prescribed relative humidity over ice.

The equations solved for heterogeneous freezing of mixed aerosol particles and associated retention effects are identical to Eqs. (5) and (6). In a mixed phase particle, the heterogeneous freezing rate is now expressed as a weighted average over the homogeneous and heterogeneous contributions (Kärcher and Lohmann, 2003):

$j_{f}=4 \pi r_{c}^{2} \Delta J_{f}\left(a_{w}+\delta a_{w}\right)+4 \pi\left(r^{3}-r_{c}^{3}\right) / 3 \cdot J_{f}\left(a_{w}\right)$

The factor $\Delta=30 \mathrm{~nm}$ accounts for different kinetic prefactors of the homogeneous and heterogeneous rate coefficents and homogeneous freezing occurs in the liquid shell surrounding the insoluble core.

In Eq. (7), almost dry nuclei freezing in the deposition mode may be included as a limiting case $\left(r_{c} \rightarrow r\right)$. Kärcher and Lohmann (2003) have suggested that the IN core volume fraction in a liquid particle is not an important parameter determining the onset of freezing in the mixed particle. Rather, the onset is largely controlled by the prescribed freezing relative humidity. In Sect. 3.5 we discuss freezing simulations carried out with the APSC.

\section{Sublimation and aerosol core return}

When ice crystals evaporate, we assume that any soluble trace species entrapped in the crystal (either through retention effects or during ice crystal growth) evaporates at a rate proportional to that of $\mathrm{H}_{2} \mathrm{O}$ molecules. This is addressed in more detail in Sect. 3.5.

The information about the initial mass of soluble and insoluble species in a freezing particle is lost as we do not track the particles individually (recall Sect.2.3). When the sublimating ice crystals have released almost all of their $\mathrm{H}_{2} \mathrm{O}$ molecules, we therefore remove them from the ice phase and reinitialize the initial (or any other) aerosol size distribution mixing ratios within one time step. To a first order, this yields a realistic description of cirrus cloud existence in subsaturated air (Ström et al., 2003). 
Restoring the aerosol particles in this way allows multiple freezing and evaporation cycles to be simulated without essential loss of accuracy regarding the freezing calculation performed with the moving-center or quasi-stationary size grids. However, the physical description of the ice-to-aerosol transition requires further improvement in studies where the lifetime and disappearence of cirrus is a main focus.

\subsection{Liquid aerosol particles: dissolution and condensation}

Dissolution occurs when a gas adsorbs on a liquid surface and dissolves in the liquid. The time evolution of the number densities $c_{\mathrm{wv}, \mathrm{a}}$ of $\mathrm{H}_{2} \mathrm{O}$ molecules residing in aerosol particles of radius $r$ (i.e., in a certain size bin) is governed by the dissolution equation

$\frac{d c_{\mathrm{wv}, \mathrm{a}}}{d t}=4 \pi D_{\mathrm{wv}} \beta_{\mathrm{wv}, \mathrm{a}} r n_{\mathrm{a}}\left(n_{\mathrm{wv}}-K_{\mathrm{wv}, \mathrm{a}} e_{\mathrm{wv}, \mathrm{a}}\right)$,

where $D_{w v}$ is the diffusion coefficient for $\mathrm{H}_{2} \mathrm{O}$ molecules in air, $\beta_{\mathrm{wv}, \mathrm{a}}$ is a size-dependent correction factor accounting for the transition between diffusion-limited $(\beta \rightarrow 1)$ and free-molecular growth regimes $(\beta \ll 1), n_{\mathrm{a}}$ is the number density of liquid aerosol particles with radius $r, n_{\mathrm{wv}}$ is the gas phase number density of $\mathrm{H}_{2} \mathrm{O}$ molecules, and the product $K_{\mathrm{wv}, \mathrm{a}} e_{\mathrm{wv}, \mathrm{a}}$ is the equilibrium vapor number density of $\mathrm{H}_{2} \mathrm{O}$ over the STS droplet.

The equilibrium vapor number density of $\mathrm{H}_{2} \mathrm{O}$ over flat STS solutions $e_{\mathrm{wv}, \mathrm{a}}$, taken from Luo et al. (1995), depends on $T$ and on the mass fractions $W_{\text {sa }}$ and $W_{\text {na }}$ of dissolved $\mathrm{H}_{2} \mathrm{SO}_{4}$ and $\mathrm{HNO}_{3}$ in the droplet of radius $r$, respectively, defined by

$$
\begin{aligned}
W_{\mathrm{sa}} & =m_{\mathrm{sa}} c_{\mathrm{sa}, \mathrm{a}} / m, \\
W_{\mathrm{na}} & =m_{\mathrm{na}} c_{\mathrm{na}, \mathrm{a}} / m, \\
m & =\sum_{l} m_{l} c_{l, \mathrm{a}} ;
\end{aligned}
$$

$m$ denotes the total droplet mass (the subscript $l$ running over all molecular species). The term $K_{\mathrm{wv}, \mathrm{a}}$ is the size-dependent Kelvin term that accounts for the enhancement of the equilibrium saturation ratio over a curved surface. The Kelvin barrier leads to a reduction of the aerosol water mass fraction in droplets smaller than $\sim 0.1 \mu \mathrm{m}$ in radius. By solving the radial gas phase diffusion equation with proper boundary conditions and matching the molecular fluxes at the gas/liquid phase boundary, one can show that $\beta_{\mathrm{wv}, \mathrm{a}}$ is given by

$$
\frac{1}{\beta_{\mathrm{wv}, \mathrm{a}}}=\frac{r}{r+\lambda}+\frac{4 D_{\mathrm{wv}}}{\alpha_{\mathrm{wv}, \mathrm{a}} \bar{v}_{\mathrm{wv}} r}
$$

with the mean free path $\lambda$ of molecules diffusing in air, the mass accomodation coefficient $\alpha_{\mathrm{wv}, \mathrm{a}}$ for $\mathrm{H}_{2} \mathrm{O}$ molecules impinging on the STS surface, and the mean thermal speed $\bar{v}_{\mathrm{wv}}$ of $\mathrm{H}_{2} \mathrm{O}$ molecules. The accomodation coefficients for all molecules condensing onto liquid STS surfaces are set equal to unity. For the numerical solution of Eq. (8) discussed in
Sect. 3.6 it is convenient to introduce a kinetic prefactor $k_{\mathrm{wv}, \mathrm{a}}$ and an effective Henry's law coefficient $H_{\mathrm{wv}, \mathrm{a}}$ via

$k_{\mathrm{wv}, \mathrm{a}}=4 \pi D_{\mathrm{wv}} \beta_{\mathrm{wv}, \mathrm{a}} r n_{\mathrm{a}} ; H_{\mathrm{wv}, \mathrm{a}}=c_{\mathrm{wv}, \mathrm{a}} /\left(K_{\mathrm{wv}, \mathrm{a}} e_{\mathrm{wv}, \mathrm{a}}\right)$.

The STS droplet number densities $n_{a}(r)$ in each bin do not change during gas uptake or evaporation. To compute the actual particle radii in each bin, the particulate volume concentrations of individual molecular species are added up and the sum is divided by the total number density to obtain the average total volume $\mathcal{V}_{k}$ of type- $k$ particles in a given bin, from which the radius can be derived:

$\mathcal{V}_{k}=\sum_{l} v_{l, k} c_{l, k} / n_{k}$,

where $v_{l, k}$ denotes the molecular volume of species $l$ in particles of type $k$.

Equations similar to Eq. (8) are solved for $\mathrm{HNO}_{3}$ and other soluble species such as $\mathrm{HCl}$ and $\mathrm{HBr}$. It must be emphasized that the nonlinear dissolution equations are strongly coupled through the composition dependence of the equilibrium vapor pressures. The particulate concentrations are also coupled to the gas phase via Eq. (1).

Condensation occurs when a gas molecule diffuses to a particle surface and changes state to a liquid. In the APSC, condensation is described by the time evolution of the number densities $c_{l, \text { a }}$ of type- $l$ molecules residing in aerosol particles of radius $r$ according to the equation

$\frac{d c_{l, \mathrm{a}}}{d t}=4 \pi D_{l} \beta_{l, \mathrm{a}} r n_{\mathrm{a}}\left[n_{l}-K_{l, \mathrm{a}} e_{l, \mathrm{a}}(T)\right]$.

The growth equations that describe condensation are similar to Eq. (8) describing dissolution. The key difference is that, for a condensing gas, the equilibrium vapor number density (or pressure) depends only on $T$ and not additionally on the particle composition. This has implications for the numerical scheme applied to solve Eq. (13), as outlined in Sect.3.6. Strictly speaking, Eq. (13) is only applicable to condensation of $\mathrm{H}_{2} \mathrm{O}$ onto pure water droplets, where $e_{l}=e_{l}(T)$. For trace species with extremely low equilibrium vapor pressures (at least under UTLS conditions), such as $\mathrm{H}_{2} \mathrm{SO}_{4}$ or $\mathrm{NH}_{3}$, the term $K_{l, \mathrm{a}} e_{l}$ is always negligible compared to the respective gas phase concentration $n_{l}$, and Eq. (8) for dissolutional growth becomes identical to Eq. (13) for condensational growth.

\section{Liquid polar stratospheric cloud}

As an application of the above dissolution equations, Fig. 1 depicts the evolution of an STS aerosol particle size distribution in a stratospheric lee wave as a function of the particle diameter $D_{p}$, as originally published by Meilinger et al. (1995). The initial background $\mathrm{H}_{2} \mathrm{SO}_{4}$ aerosol size distribution is lognormal (total number density $10 \mathrm{~cm}^{-3}$, mode radius $80 \mathrm{~nm}$, and width 1.8 ), the initial temperature and pressure is $196 \mathrm{~K}$ and $65 \mathrm{hPa}$. The air contains total 


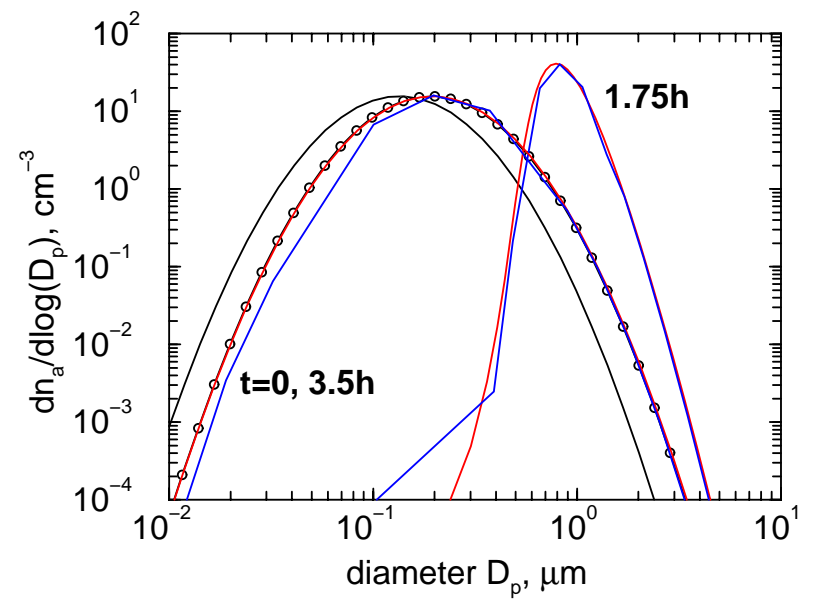

Fig. 1. Evolution of a lower stratospheric aerosol size distribution into a liquid PSC in an idealized mesoscale lee wave. The particles were discretized over 50 bins with a bin volume ratio of 1.7 . The total simulation time was $3.5 \mathrm{~h}$, the initial and final temperature was $196 \mathrm{~K}$. Between $t=1-2 \mathrm{~h}, T=190 \mathrm{~K}$, achieved by cooling/heating with a constant cooling/heating rate of $6 \mathrm{~K} \mathrm{~h}^{-1}$ before $1 \mathrm{~h} /$ after $2 \mathrm{~h}$, respectively. The black solid curve is the dry initial size distribution at $t=0$, composed of $0.286 \mathrm{ppb}$ of $\mathrm{H}_{2} \mathrm{SO}_{4}$. The black solid curve with circles is the wet initial size distribution in equilibrium with ambient $\mathrm{H}_{2} \mathrm{O}$. The colored curves are taken at $1.75 \mathrm{~h}$ and $3.5 \mathrm{~h}$, and are calculated with a hybrid size grid (red) and a moving-center grid (blue). At $1.75 \mathrm{~h}$, the particles have grown dramatically by coupled uptake of $\mathrm{HNO}_{3}$ and $\mathrm{H}_{2} \mathrm{O}$, and around $80 \%$ of the available $\mathrm{HNO}_{3}$ is partitioned into STS particles. At $3.5 \mathrm{~h}$, the size distributions have relaxed back to their initial wet state.

mixing ratios of $5 \mathrm{ppm} \mathrm{H}_{2} \mathrm{O}$ and $10 \mathrm{ppb} \mathrm{HNO}_{3}$. An idealized mesoscale lee wave reduces $T$ linearly down to $190 \mathrm{~K}$ within the first hour at a constant rate of $-6 \mathrm{~K} \mathrm{~h}^{-1}$, keeps $T$ constant at $190 \mathrm{~K}$ for one hour, and increases $T$ linearly to $196 \mathrm{~K}$ at $6 \mathrm{~K} \mathrm{~h}^{-1}$ in the third hour, staying constant thereafter.

At $t=0$, the particles equilibrated with ambient $\mathrm{H}_{2} \mathrm{O}$, resulting in the wet size distribution shown as a black solid curve with circles (the corresponding dry curve is shown in black without circles). During the cooling phase, a liquid PSC is forming, as the background aerosol takes up most of the available $\mathrm{HNO}_{3}$ and forms STS particles. After $1.75 \mathrm{~h}$, the STS mean number (volume) radius is $0.45(0.53) \mu \mathrm{m}$ (colored curves at $1.75 \mathrm{~h}$ ). Very few of the smallest STS particles (less than $\sim 0.001 \mathrm{~cm}^{-3}$ ) lag behind during growth. The moving center distribution becomes very coarse at small sizes. The last visible grid point in Fig. 1 (blue curve) belongs to STS particles with $D_{p}=0.39 \mu \mathrm{m}$; the next grid point (not visible) belongs to $D_{p}=6 \mathrm{~nm}$ and very low concentrations $\left(\sim 10^{-7} \mathrm{~cm}^{-3}\right)$; growth of the latter particles is hindered by the Kelvin barrier. A similar effect occurs in the hybrid grid simulation (red curve), but is less obvious in Fig. 1. When $T$ and $p$ return to their initial values after $3 \mathrm{~h}$, the particles have evaporated the dissolved molecules and shrink to their initial wet sizes (colored curves at $3.5 \mathrm{~h}$ ).

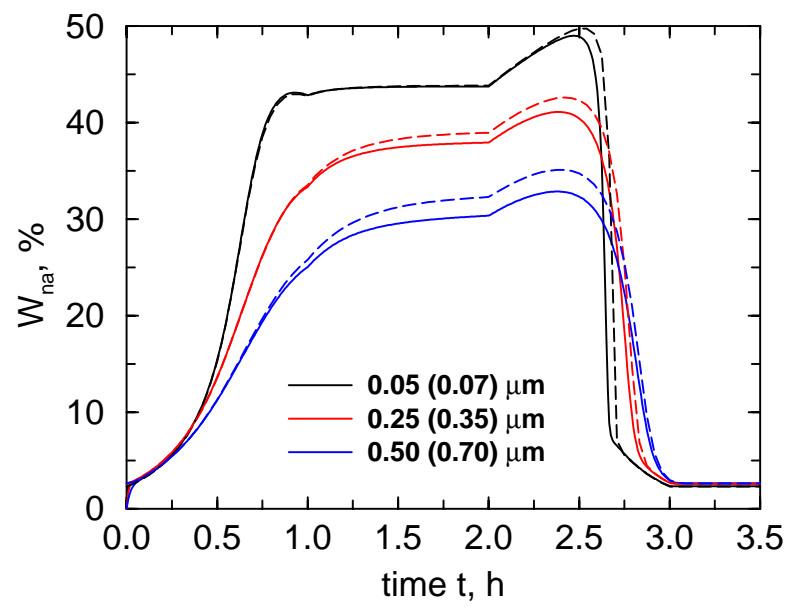

Fig. 2. The evolution of $\mathrm{HNO}_{3}$ mass fraction in STS particles with different dry (wet) radii as indicated in the legend for the lee wave simulation performed with the hybrid size grid (solid curves) as displayed in Fig. 1. The kinks in $W_{\text {na }}(t)$ at $t=1 \mathrm{~h}$ and $2 \mathrm{~h}$ arise from the ubrupt changes of $d T / d t$. The dashed curves are results from a Lagrangian PSC model (data courtesy of S. Meilinger).

The results obtained with the hybrid grid (red curves) and with the moving-center grid (blue curves) are virtually free of numerical diffusion. With the hybrid grid, the STS particles relax exactly back to their initial wet sizes after $3.5 \mathrm{~h}$, as the particles are not distributed over several bins and the information about the initial state of the aerosol is memorized in this Lagrangian approach. In contrast, the number of size bins representing the STS particles decreases as a function of time in the moving-center simulations, resulting in a poorer resolution of the size distribution in the small size portion.

Figure 2 presents the time history of $W_{\text {na }}$ for three particles whose initial dry and wet radii are indicated in the legend (solid curves). Initially, only little $\mathrm{HNO}_{3}$ is dissolved in the aerosol particles. With ongoing cooling, $W_{\text {na }}$ increases. After $0.5 \mathrm{~h}$, the rate of increase becomes faster the smaller the droplets are, which is caused by diffusive limitation of the vapor fluxes to the large particles. The mass fractions level off after the cooling stopped at $1 \mathrm{~h}$ and $T$ is held constant. At $2 \mathrm{~h}$, the air parcel temperature rises, but before the mass fractions drop, they increase rapidly and take on their maximum values around $2.5 \mathrm{~h}$. This effect is caused by the pronounced difference between the time scales for evaporation of $\mathrm{HNO}_{3}$ and $\mathrm{H}_{2} \mathrm{O}$ molecules (the latter leave the particles quicker than the former), as outlined by Meilinger et al. (1995).

The APSC results can be compared to numerical results obtained with the Lagrangian code developed by Meilinger et al. (1995), the latter being plotted as dashed lines in Fig. 2 (data from S. Meilinger, personal communication, 2003). Both models produce the same overall behavior of $W_{\mathrm{na}}(\mathrm{t})$, although the dashed curves reach somewhat higher mass fractions, especially for larger particles. This is probably caused by slight differences in the underlying vapor pressures. 


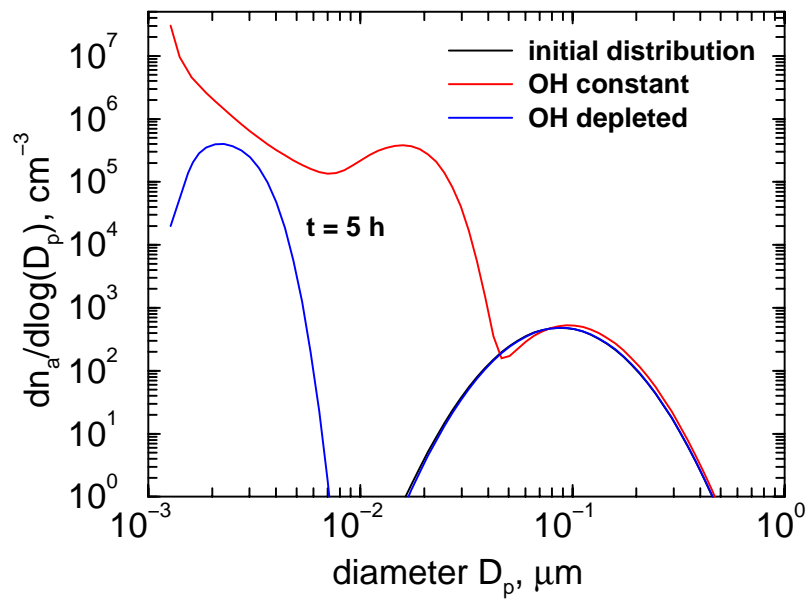

Fig. 3. Size distributions of $\mathrm{H}_{2} \mathrm{SO}_{4} / \mathrm{H}_{2} \mathrm{O}$ particles developing in a chemically-induced nucleation burst in the outflow of a deep convective cloud at $200 \mathrm{hPa}$ and $215 \mathrm{~K}$. The particles were discretized over 80 bins with a bin volume ratio of 1.3. The black curve is the initial spectrum, the colored curves are snapshots taken $5 \mathrm{~h}$ later. The mixing ratio of $\mathrm{OH}$ is held constant at 2 ppt (red curve) or is completely depleted by reaction with $\mathrm{SO}_{2}$ during the burst phase that occurs in the first minutes (blue curve). Nucleation, coagulation, and condensation processes occur simultaneously.

\subsection{Coagulation}

The general form of the coagulation equation reads (here $n \equiv n_{k}$ denotes the number density of type- $k$ particles):

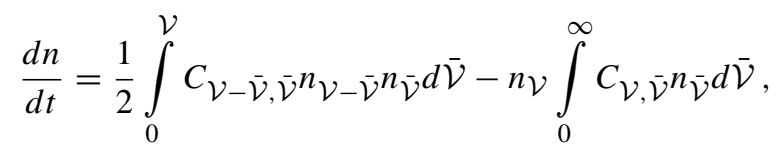

where $\mathcal{V}-\overline{\mathcal{V}}$ and $\overline{\mathcal{V}}$ are the volumes of two coagulating particles, $\mathcal{V}$ is the volume of the coagulated particle and $C$ is the coagulation rate coefficient. Brownian rate coefficients for coagulation between aerosol particles in the transition regime are implemented in the APSC, consistent with the transitional factor for growth from Eq. (10) (Jacobson, 1999).

In the APSC, Eq. (14) is extended to describe coagulation over multiple (one aerosol and one ice) particle size distributions using either the quasi-stationary or the hybrid size structure with variable bin volume ratios. Details of this extension are provided by Jacobson (1999). Using the stationary grid, two coagulating particles form a larger particle a fraction of which is partitioned between two adjacent bins. Using the hybrid grid, two coagulating particles become a larger particle whose core volume (not total volume) is partitioned between two bins. Hetero-coagulation between aerosol and ice particles is allowed based on Brownian motion, but additional coagulation rate coefficients (caused by gravitational collection, turbulent inertial motion, and wind shear) may be required to study collisional aerosol-ice interactions in more detail.
Nucleation can be induced by cooling, mixing of air parcels, or chemical production of aerosol precursor gases. The freshly nucleated particles may grow by coagulation or condensation. Coagulational growth is important when their number density is sufficiently high. Condensational growth is important when enough vapor is available, either because nucleation has not fully removed the nucleating gases or condensable gases are present that did not participate in the nucleation process. In nucleation events triggered by cooling or mixing, coagulational growth typically dominates over condensation shortly after particle formation. In events triggered by chemical reactions, condensation may be equally important or dominate over coagulation depending on the rate at which condensable material is produced.

\section{Upper tropospheric nucleation burst}

As an application of the above nucleation, coagulation, and condensation equations, the formation of upper tropospheric aerosol particles observed in the outflow of a midlatitude storm (Twohy et al., 2002) is examined. The observations took place downwind of a mesoscale convective system stretching across much of the central United States of America and revealed dramatic enhancements in concentrations of small aerosol particles over at least a $600 \mathrm{~km}$ region. The burst of new particles likely occurred in a continuous stream of convected air emerging from the storm.

The present case considers nucleation induced by chemical oxidation of $\mathrm{SO}_{2}$ lifted into the UTLS region via deep convection. The particle formation event has been analyzed with the help of analytic models for nucleation, condensation, and coagulation of $\mathrm{H}_{2} \mathrm{SO}_{4} / \mathrm{H}_{2} \mathrm{O}$ particles (Clement et al., 2002); the APSC results are also compared with the inferences from the analytic approach.

Guided by the observations, the APSC simulations have been initialized as follows: $p=200 \mathrm{hPa}, T=215 \mathrm{~K}$, $\left[\mathrm{SO}_{2}\right]=1 \mathrm{ppb},[\mathrm{OH}]=2 \mathrm{ppt},\left[\mathrm{H}_{2} \mathrm{O}\right]=50 \mathrm{ppm}$, background aerosol number density $250 \mathrm{~cm}^{-3}$, dry mean number radius $0.03 \mu \mathrm{m}$, and geometric width 1.6. The latter two parameters and the mixing ratio of $\mathrm{SO}_{2}$ have been estimated. As the time evolution of the chemical species and the overall mixing ratio of $\mathrm{SO}_{2}$ are uncertain, the use of the simple $\mathrm{OH}$-mediated chemistry described in Sect. 2.2 without photolysis reactions is justified. The observed number density of new particles with radii $>12.5 \mathrm{~nm}$ is $\sim 1.2 \times 10^{4} \mathrm{~cm}^{-3}$ several hours after the burst.

The analytical results are: maximum number density of new particles produced in the burst $7 \times 10^{6} \mathrm{~cm}^{-3}$, duration of the burst $\sim 5 \mathrm{~min}$, and age of the observed particles $5 \pm 2.5 \mathrm{~h}$ after the burst. The dependence on initial $\mathrm{SO}_{2}$ concentrations is weak, provided the resulting chemical production rate of $\mathrm{H}_{2} \mathrm{SO}_{4}$ does not extend to such small values where nucleation will be cut off. 

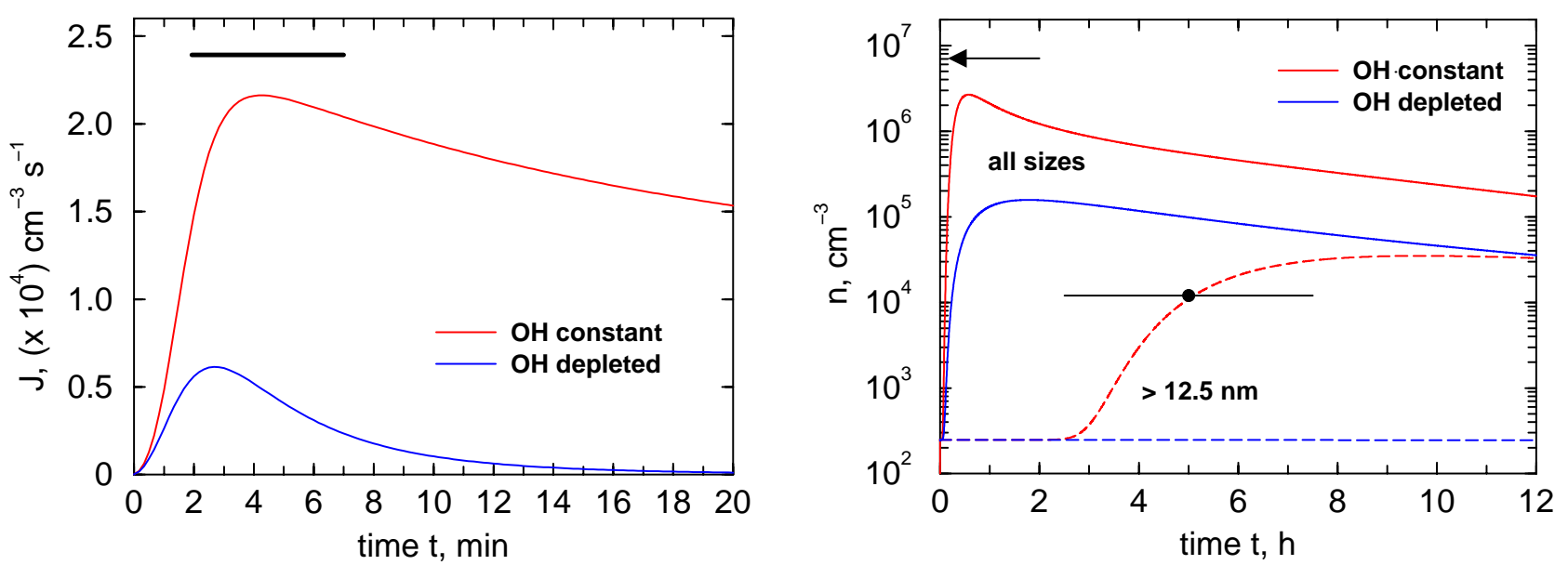

Fig. 4. Time history of the nucleation burst as described in Fig. 3. The left panel shows the binary homogeneous nucleation rate coefficient $J$ in the first $20 \mathrm{~min}$ along with the duration of the burst (thick line) estimated from an analytic model (Clement et al., 2002). the right panel shows the number densities of all particles (solid curves) and of all particles greater than $12.5 \mathrm{~nm}$ in radius (dashed curves), along with the peak number of nucleated particles (arrow) estimated from theory and the observed concentration of condensation nuclei (circle with estimated uncertainty of the age of the probed air mass). The mixing ratio of $\mathrm{OH}$ is held constant at 2 ppt (red curves) or is completely depleted by reaction with $\mathrm{SO}_{2}$ during the burst phase (blue curves).

The number density of newly formed aerosol particles is not sensitive to variations of the background aerosol parameters in this case, as scavenging losses are small on the time scale of several hours considered here. This may be regarded as typical for the UTLS region with relatively low background aerosol surface area densities (de Reus et al., 1998; Kärcher and Solomon, 1999). In contrast, many field measurements performed in the middle and lower troposphere indicate that the higher aerosol surface area there can have a crucial effect on onset and intensity of nucleation as well as on particle growth beyond nanometer sizes (e.g., Kerminen et al., 2001).

The aerosol size distributions obtained with the APSC are shown in Fig. 3. The black distribution defines the initial aerosol spectrum, the colored curves are taken five hours later. The red curve assumes that the $\mathrm{OH}$ mixing ratio stays constant over a $12 \mathrm{~h}$ simulation period, while the blue curve assumes that all available $\mathrm{OH}$ is depleted by reactions with $\mathrm{SO}_{2}$. Both assumptions can be considered as extreme cases: the former may overestimate the total amount of $\mathrm{OH}$ molecules available to produce $\mathrm{H}_{2} \mathrm{SO}_{4}$ and the latter surely underestimates this amount as other fast radical reactions will maintain at least an $\mathrm{OH}$ level of perhaps a fraction of a ppt.

In the blue case, a single nucleation mode is generated in the ultrafine size range. The initial size of the new particles is near $1 \mathrm{~nm}$. New particle formation ceases when all available $\mathrm{OH}$ is consumed, and the nucleation mode grows exclusively by coagulation thereafter. After $5 \mathrm{~h}$, the mean radius of the nucleation mode is still in the cluster size range $\sim 2 \mathrm{~nm}$. In the red case, we observe two nucleation modes. The first mode peaks towards the smallest sizes. This indicates that nucleation is ongoing and scavenging losses on larger aerosol particles are not large enough to compete with nucleation owing to the high chemical production rate of $\mathrm{H}_{2} \mathrm{SO}_{4}$ up to $\sim 10^{5} \mathrm{~cm}^{-3} \mathrm{~s}^{-1}$. A combination of condensational growth and coagulation produces a second mode that has grown to a mean radius of $\sim 10 \mathrm{~nm}$ after $5 \mathrm{~h}$.

As in the case of $\mathrm{HNO}_{3}$ dissolving into STS particles, uptake of $\mathrm{H}_{2} \mathrm{SO}_{4}$ is always accompanied by dissolution of $\mathrm{H}_{2} \mathrm{O}$ molecules in order to maintain equilibrium between the particles and the ambient relative humidity.

Figure 4 provides more details of the particle evolution (color coding as in the previous figure). The left panel depicts the homogeneous nucleation rate coefficient as a function of time. The solid bar marks the approximate duration of the burst $(5 \mathrm{~min})$ from the analytic analysis. Both red and blue curves support this result, but the blue curve is more burst-like as it rapidly decays after $\mathrm{OH}$ is depleted and no more $\mathrm{H}_{2} \mathrm{SO}_{4}$ becomes available after $\sim 20 \mathrm{~min}$. The red curve shows that a constant level of $\mathrm{OH}$ keeps the nucleation rate fairly high at values $\sim 10^{4} \mathrm{~cm}^{-3} \mathrm{~s}^{-1}$ over many hours, explaining the persistence of the leftmost mode seen in Fig. 3 (red curve).

The right panel in Fig. 4 depicts the total number of aerosol particles (solid curves) and the cumulative number of particles larger than $12.5 \mathrm{~nm}$ in radius (dashed curves) as a function of time. The arrow marks the analytic estimate of the peak number of new particles produced in the burst, and the black circle marks the estimated age of the air mass (along with error bounds) at the time of the measurements (Clement et al., 2002). It is obvious that nucleation is too weak in the case where $\mathrm{OH}$ is not chemically replenished, as neither the estimated peak total concentration nor the measured cumulative concentration is reproduced. In contrast, the red case is 
consistent with the observations, although we have not convolved the condensation particle counting efficiency with the calculated particle numbers (this would slightly shift the increasing branch of the red dashed curve to later times).

The relatively good agreement between observations, analytic model, and APSC simulation suggests that $\mathrm{OH}$ must have been present in high concentrations over many hours in order to explain the growth of the new particles into the measurement range. According to the simulations, this implies that nucleation continued after the burst phase. However, as experimental information is limited, alternative explanations cannot be excluded. The requirement of a strong, persistent source of $\mathrm{OH}$ could be relaxed if a sufficient amount of condensable material other than $\mathrm{H}_{2} \mathrm{SO}_{4}$ was present. As ice particles form frequently in the outflow regions of convective systems (anvil cirrus), scavenging of fresh aerosol particles by cirrus ice crystals may lead to a reduction of the aerosol concentration along with reduced coagulational growth.

In summary, the numerical simulations highlight that more detailed simultaneous observations of chemical species, relative humidity, temperature, and particle properties (including their temporal evolution) are required to better understand nucleation events in the UTLS region.

3.5 Ice crystals: depositional growth, trapping of trace gases, and sedimentation

Condensation on solid surfaces is termed deposition. The time evolution of the number densities $c_{\mathrm{wv}, \mathrm{i}}$ of $\mathrm{H}_{2} \mathrm{O}$ molecules residing in ice crystals of radius $r$ is governed by the deposition equation

$$
\frac{d c_{\mathrm{wv}, \mathrm{i}}}{d t}=4 \pi D_{\mathrm{wv}} \beta_{\mathrm{wv}, \mathrm{i}} \kappa_{\mathrm{i}} \phi_{\mathrm{i}} n_{\mathrm{i}}\left[n_{\mathrm{wv}}-K_{\mathrm{wv}, \mathrm{i}} e_{\mathrm{wv}, \mathrm{i}}(T)\right],
$$

with the notation similar to Eq. (13), except that $r$ is now included in $\kappa_{\mathrm{i}}$ (see below). The equilibrium vapor pressure over a plane ice surface $e_{\mathrm{wv}, \mathrm{i}}$ is taken from Marti and Mauersberger (1993). The functions $\kappa_{\mathrm{i}}$ and $\phi_{\mathrm{i}}$ represent corrections due to the possible non-sphericity of ice crystals (capacitance) and due to increased rate of vapor transfer to the upstream surface of large, sedimenting crystals (ventilation factor), respectively.

Ice crystals with radii below $7.5 \mu \mathrm{m}$ are assumed to be spherical. This is a reasonable assumption for pristine upper tropospheric cirrus particles. The mean roundness of observed ice crystals increases with decreasing $T$, indicating quasi-spherical ice particles with mean sizes in the range 20$30 \mu \mathrm{m}$ at $T=233-238 \mathrm{~K}$ (Korolev and Isaac, 2003). Replicator images of ice crystals in the radius range $5-10 \mu \mathrm{m}$ taken at $T=218-223 \mathrm{~K}$ also support this notion (Schröder et al., 2000, their Fig. 3d).

Ice crystals with radii above $12.5 \mu \mathrm{m}$ are assumed to be columns with an aspect ratio $\mathcal{A}=\ell / d$, defined as the ratio between the crystal length $\ell$ and its diameter $d$. Ice particle habits in noctilucent clouds are likely equidimensional cubic or hexagonal crystals owing to the very low temperatures of 110-160 K prevailing at the mesopause (Turco et al., 1982). Ice particles observed in polar stratospheric clouds can be approximated by hexagonal columns with $\mathcal{A}=1-5$ (Goodman etal., 1989). The situation is less clear in the case of cirrus particles. It is known that cirrus ice crystals can take many different shapes, depending on their life cycle (Miloshevich and Heymsfield, 1997; Wang, 2002); however, columnar shapes are certainly among the more common types of ice crystal shapes in the upper troposphere (Korolev and Isaac, 2003).

In the APSC, we allow $\mathcal{A}$ to take the values $1,2,3$, and 10. In the size range between $7.5 \mu \mathrm{m}$ and $12.5 \mu \mathrm{m}$, we use linear interpolations of $\kappa_{\mathrm{i}}$ and $\phi_{\mathrm{i}}$ to ensure a smooth transition between the spherical and non-spherical approximations.

For spherical particles, $\kappa_{\mathrm{i}}=r$. For non-spherical particles, we use the capacitance of a column (Jacobson, 1999, p.473):

$\kappa_{\mathrm{i}}=\sqrt{\mathcal{A}^{2}-1}\left[\ln \left(\frac{\mathcal{A}+\sqrt{\mathcal{A}^{2}-1}}{\mathcal{A}-\sqrt{\mathcal{A}^{2}-1}}\right)\right]^{-1} d$.

Note that $\kappa_{i} \rightarrow d / 2$ when $\mathcal{A} \rightarrow 1$. In the following, we assume that the columns have hexagonal cross sections. Noting that the surface area of a hexagon with the base circumscribed radius $d / 2$ is given by $S=(3 / 4)^{3 / 2} d^{2}$, the relationship between $d$ and $r$ (the radius of the volume-equivalent sphere) is given by

$\frac{4 \pi}{3} r^{3}=S \ell \quad \Longrightarrow \quad d=\left[\left(\frac{4}{3}\right)^{5 / 2} \frac{\pi}{\mathcal{A}}\right]^{1 / 3} r$.

The dependence of $\ell$ on $\mathcal{A}$ can easily be derived via $\ell=\mathcal{A} d$ using Eq. (17). The capacitance corrects the growth rate of a non-spherical particle only in the diffusion limit. In this case, we use the modified transitional correction factor

$\frac{1}{\beta_{\mathrm{wv}, \mathrm{i}}}=\frac{r}{r+\lambda}+\frac{4 D_{\mathrm{wv}} \kappa_{0}}{\alpha_{\mathrm{wv}, \mathrm{i}} \bar{v}_{\mathrm{wv}} r}$,

that replaces Eq. (10) for spherical particles. Here, $\kappa_{0}$ is defined as $\kappa_{\mathrm{i}}=\kappa_{0} r$ by the combination of Eqs. (16) and (17). We set $\alpha_{\mathrm{wv}, \mathrm{i}}=0.5$ (Haynes et al., 1992; Warshawsky et al., 1999; Haag et al., 2003a; Kärcher and Ström, 2003). We use the radius of a volume-equivalent sphere computed from Eq. (12) to calculate the Kelvin term and the transition factor in Eq. (15). As both corrections begin to deviate significantly from unity only for $r<1-10 \mu \mathrm{m}$ and we assume such small crystals to be spherical (see above), the distinction between true spherical radius and radius of a volume-equivalent sphere is not important in this case.

For spherical particles, we employ the ventilation coefficient for spherical drops (Pruppacher and Klett, 1997, p.541). Values of $\phi_{\mathrm{i}}$ for hexagonal columns are computed using a relationship for columnar crystals (Pruppacher and Klett, 1997, p.553). In both cases, $\phi_{\mathrm{i}}$ is parameterized as a function of the Reynolds (Re) and Schmidt (Sc) numbers characterizing the flow field around settling ice crystals. The dependence of $\phi_{\mathrm{i}}$ is of the form $\phi_{\mathrm{i}}(X)$, where $X=\mathrm{Re}^{1 / 2} \mathrm{Sc}^{1 / 3}$. The Schmidt 
number is a simple function of air temperature and pressure. The Reynolds number contains a dependence on the crystal habit and hence depends on $\mathcal{A}$.

The scheme used to compute Re works as follows. We first compute the Best number Be according to

$\mathrm{Be}=\frac{8 m_{i}}{\pi} \frac{\rho}{\eta^{2}}, \quad \operatorname{Be}(\mathcal{A})=\frac{2 m_{i}}{\mathcal{A}} \frac{\rho}{\eta^{2}} ;$

the left equation assumes spheres and the right equation assumes hexagonal columns. Here, $m_{i}$ is the crystal mass, $\rho$ and $\eta$ are the mass density and dynamic viscosity of air, respectively. Then, we use the relationships $\operatorname{Re}(\mathrm{Be})$ provided by Pruppacher and Klett (1997) (p. 417 for spheres and p. 430 for columns) to compute the Reynolds number and from it the variable $X$ and hence $\phi_{\mathrm{i}}(X)$.

In view of further model extensions addressing gravitational settling of large ice crystals (see Sect.4), it will become necessary to compute sedimentation velocities of ice crystals in free fall. Particles with sizes of interest $(0.5 \mu \mathrm{m}<r<500 \mu \mathrm{m})$ undergo stable fall and establish equilibrium between gravitational and drag forces in fractions of a second. Their terminal fall speed $w$ is governed by the Reynolds number of the flow around the falling particle.

Small particles fall in the Stokes-Cunningham regime:

$w=\frac{2 r^{2} g\left(\rho_{i}-\rho\right)}{9 \eta f_{1}} S, \quad S=1+f_{2} \operatorname{Kn}\left(c_{1}+c_{2} e^{-c_{3} / \mathrm{Kn}}\right)$

here $g$ is the acceleration of gravity, $\rho_{i}$ is the mass density of ice particles, and $\mathrm{Kn}$ is the Knudsen number $\lambda / r$. The Cunningham correction for slip-flow $S$ accounts for gas kinetic effects near the particle surface, with the parameters $c_{1}=1.246, c_{2}=0.42$, and $c_{3}=0.87$. The shape correction factors $f_{1}$ and $f_{2}$ (Toon et al., 1989) are introduced to match the results with the fall speed for large particles (see below). We set $f_{1}=f_{2}=1$ for spheres and columns with $\mathcal{A}=1,2$; $f_{1}=1.12, f_{2}=0.52$ for $\mathcal{A}=3 ; f_{1}=1.65, f_{2}=0.15$ for $\mathcal{A}=10$. Equation (20) holds for $\operatorname{Re}<0.01$, that is, for particles with $r<10 \mu \mathrm{m}$. Recall that we assume all particles below $7.5 \mu \mathrm{m}$ to be spherical.

Large particles fall in the Oseen-Best regime:

$w=\frac{\eta}{\rho d} \operatorname{Re}$

where Re and $d$ depend on the ice cyrstal habit as described above. Equation (21) is valid in the range $0.01<\operatorname{Re}<300$, that is, for particles with $10 \mu \mathrm{m}<r<500 \mu \mathrm{m}$. Larger particles no longer undergo stable fall. Uptake of gas molecules other than $\mathrm{H}_{2} \mathrm{O}$ (see below) will not substantially alter the mass per ice particle and does not affect the sedimentation velocities. Terminal fall speeds, ventilation coefficients, and capacitances are discussed further in the Appendix.

Ice crystals may interact with trace gases such as $\mathrm{HNO}_{3}$, $\mathrm{HCl}$, and $\mathrm{HO}_{2}$ by adsorption and perhaps subsequent heterogeneous chemical reactions. A meaningful application of the concept of adsorption requires steady surface properties. When ice particles exist under ice-saturated (static) conditions, $\mathrm{H}_{2} \mathrm{O}$ molecules will adsorb and desorb at equal rates. Laboratory studies have shown that such ice surfaces are highly dynamic, even at very low temperatures; for equilibrium conditions, adsorption and desorption rates of 10 1000 monolayers (one monolayer corresponds to $\sim 10^{15} \mathrm{H}_{2} \mathrm{O}$ molecules per $\mathrm{cm}^{2}$ of surface) per second have been measured for $T=180-210 \mathrm{~K}$ (Haynes et al., 1992).

Consequently, a rapid build-up of ice layers by impinging $\mathrm{H}_{2} \mathrm{O}$ molecules will take place if the ice particles experience supersaturation. Under such highly dynamic conditions, it is conceivable that the concept of an adsorption equilibrium coverage is not appropriate. Rather, we envisage that the trace gas molecules will attach to the surfaces only transiently and will become buried by layers of deposited $\mathrm{H}_{2} \mathrm{O}$ molecules. Owing to the very low diffusivities in bulk ice, the trace species will be released to the gas phase only when $\mathrm{H}_{2} \mathrm{O}$ molecules evaporate again under subsaturated conditions.

To account for trace gas scavenging by growing ice crystals, we implement a burial coefficient $B_{l}$ that describes different efficiencies of gas trapping under supersaturated conditions in the spirit of Yin et al. (2002). The value of $B_{l}$ will be close to unity for molecules that adsorb chemically (dissociate or react) on a static ice surface, because such molecules will have a relatively long residence time before desorption. These molecules generally have high deposition coefficients $\alpha_{l, \mathrm{i}} \rightarrow 1$. An example for a molecule dissociating on ice is $\mathrm{HNO}_{3}$. Gases with weak (physical) surface interaction desorb roughly at a rate comparable to that of $\mathrm{H}_{2} \mathrm{O}$ molecules and will tend to have low values of both, $B_{l}$ and $\alpha_{l, i}$.

The equation for the time evolution for non-reactive uptake of type- $l$ molecules (we identify $l$ with $\mathrm{HNO}_{3}$ for illustration) reads

$\frac{d c_{\mathrm{na}, \mathrm{i}}}{d t}=4 \pi D_{\mathrm{na}} \beta_{\mathrm{na}, \mathrm{i}} \kappa_{\mathrm{i}} \phi_{\mathrm{i}} n_{\mathrm{i}} n_{\mathrm{na}}, \quad \frac{d c_{\mathrm{wv}, \mathrm{i}}}{d t}>0$,

with the notation similar to Eq. (15), except that we abandoned the equilibrium vapor pressure term. The burial coefficient $B_{\text {na }}$ is set equal to $\alpha_{\text {na,i }}$ (Yin et al., 2002), which enters the transitional correction factor for $\mathrm{HNO}_{3}$ molecules impinging on ice surfaces:

$\frac{1}{\beta_{\mathrm{na}, \mathrm{i}}}=\frac{r}{r+\lambda}+\frac{4 D_{\mathrm{na}} \kappa_{0}}{B_{\mathrm{na}} \bar{v}_{\mathrm{na}} r}$,

Values $B_{\text {na }}<1$ imply that a fraction of the $\mathrm{HNO}_{3}$ molecules striking the ice surface become buried. Equation (22) predicts that $\mathrm{HNO}_{3}$ co-condenses with $\mathrm{H}_{2} \mathrm{O}$ whenever the particles are supersaturated with respect to the ice phase.

It is clear that $B_{l}$ should depend on the relative time scales of deposition of $\mathrm{H}_{2} \mathrm{O}$ molecules and desorption of the trace species and hence on $T, n_{l}$, on the energy of activation for desorption, on the diffusivity of the molecules through the growing ice multilayers, and perhaps on other factors. However, as for the retention coefficient (recall Sect. 3.2), a 

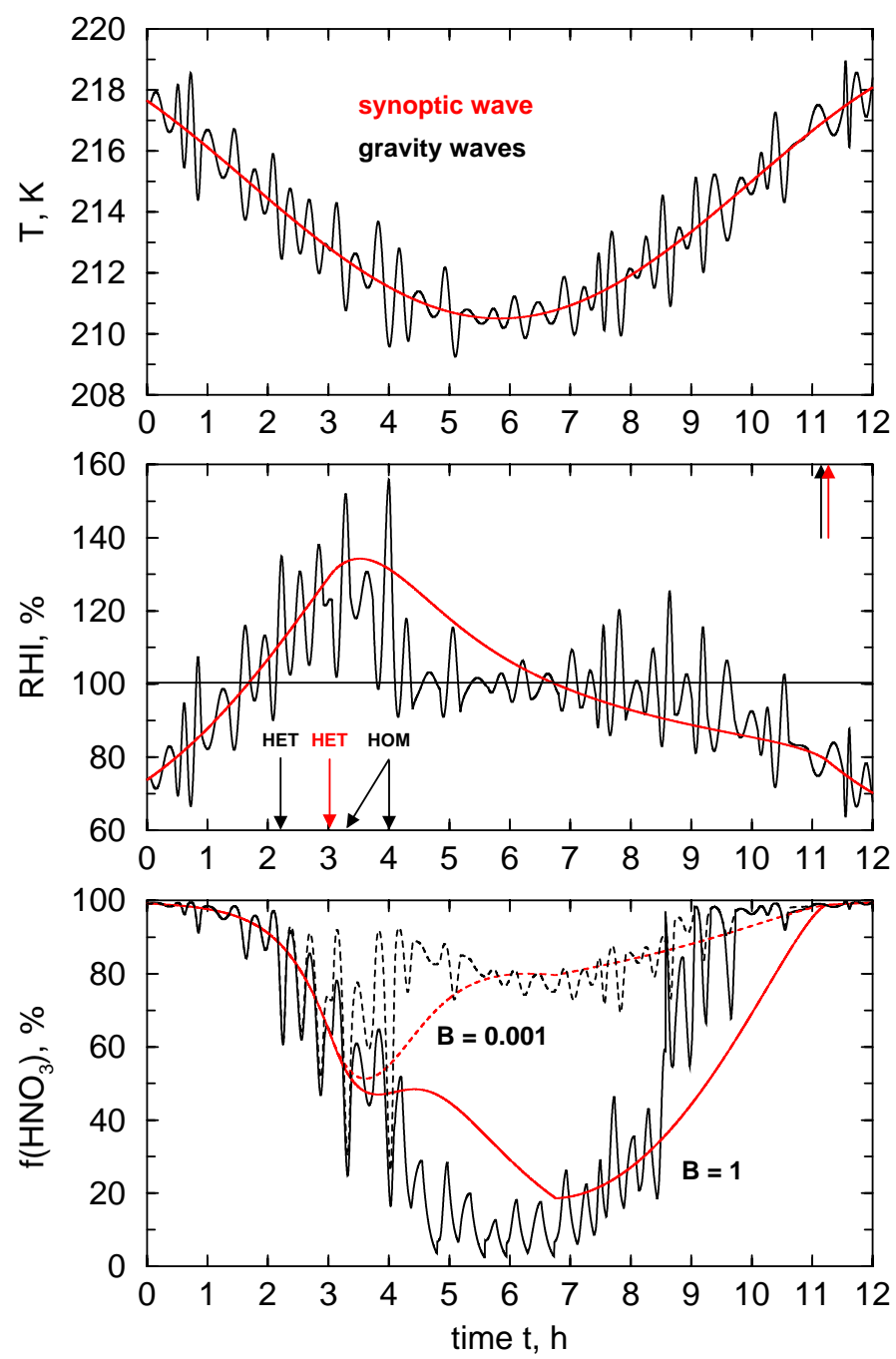

Fig. 5. Temporal evolution of cirrus clouds starting at $218 \mathrm{~K}$ and $\sim 220 \mathrm{hPa}$ forced by cooling due to a synoptic wave with (black curves) and without (red curves) superimposed gravity waves. The top, middle, and bottom panel show the temperature, the relative humidity over ice, and the fraction of gas phase $\mathrm{HNO}_{3}$, respectively. The buoyancy waves have random temperature amplitudes, uniformly distributed in the range $0-2 \mathrm{~K}$, and random, normally-distributed periods with a mean value of $1200 \mathrm{~s}$ and a standard deviation of $400 \mathrm{~s}$. The liquid background aerosol consists of $\mathrm{H}_{2} \mathrm{SO}_{4} / \mathrm{H}_{2} \mathrm{O}$ droplets that form STS solutions during cooling. The heterogeneous ice nuclei do no interact with the gas phase and are allowed to freeze (label HET) around a relative humidity over ice of 130\%. Homogeneous freezing (label HOM) occurs two times at $150-160 \%$. The total mixing ratio of $\mathrm{HNO}_{3}$ is $0.5 \mathrm{ppb}$. Ice crystals nucleate first heterogeneously on IN and then homogeneously on the liquid particles in the case with gravity waves; they nucleate only on IN in the case of synoptic cooling (bottom arrows in the middle panel). Both clouds evaporate almost at the same time as the air mass warms (top arrows in the middle panel). The solid (dashed) curves in the bottom panel assume a burial efficiency of $1(0.001)$ for $\mathrm{HNO}_{3}$ uptake on ice crystals.

theoretical model for the burial coefficient is not available, justifying the use of this simplified description $\left(B_{l}=\alpha_{l, \mathrm{i}}\right)$ in current models.

Nitric acid will evaporate from ice along with $\mathrm{H}_{2} \mathrm{O}$ molecules when the particles are subsaturated with respect to the ice phase. Under the assumption that the entrapped trace gas is uniformly distributed in the ice volume, a reasonable estimate for the evaporation rate of $\mathrm{HNO}_{3}$ molecules in an ice particle of size $r$ is given by

$$
\frac{d c_{\mathrm{na}, \mathrm{i}}}{d t}=\frac{c_{\mathrm{na}, \mathrm{i}}}{c_{\mathrm{wv}, \mathrm{i}}} \frac{d c_{\mathrm{wv}, \mathrm{i}}}{d t}, \quad \frac{d c_{\mathrm{wv}, \mathrm{i}}}{d t}<0
$$

similar equations can be formulated for other trace species trapped in ice. Finally, it is argued that atmospheric air parcels will only rarely experience conditions where $d c_{\mathrm{wv}, \mathrm{i}} / d t \approx 0$ (see Fig. 5 , middle panel) and a possible 
coverage of $\mathrm{HNO}_{3}$ on the (almost) static ice surfaces is ignored in this case.

The presence of trace substances such as $\mathrm{HNO}_{3}$ on an ice surface may slow the evaporation rates of $\mathrm{H}_{2} \mathrm{O}$ molecules from ice particles. Such a mechanism has been proposed to explain stratospheric denitrification caused by PSCs without dehydration (Wofsy et al., 1990). However, there is mixed laboratory evidence for such an effect, especially for $\mathrm{HNO}_{3}$ partial pressures more typical for the UTLS in regions where cirrus form (Warshawsky et al., 1999, and references therein). In addition, there is lacking field evidence for a reduction of ice evaporation rates in cirrus. For these reasons, the presence of $\mathrm{HNO}_{3}$ on ice surfaces is currently assumed to have no impact on ice evaporation rates in the APSC.

\section{Gravity waves, Twomey effect, and nitric acid scavenging in cirrus}

It has been suggested that mesoscale temperature fluctuations can affect the nucleation and growth of PSC particles (Murphy and Gary, 1995). Gravity waves also seem to play a crucial role in cirrus formation, as demonstrated in recent analyses of airborne measurements (Kärcher and Ström, 2003). Figure 5 depicts the calculated time history of cirrus clouds forming out of STS droplets and ice nuclei under different dynamical forcings. In the simulation, mesoscale buoyancy waves with random amplitudes and frequencies (black curves) are superimposed on a synoptic wave (red curves). The assumed wave properties as noted in the figure caption lead to frequency distributions of updraft speeds and ice crystal number densities consistent with those taken during the airborne measurements (Kärcher and Ström, 2003). The top, middle, and bottom panel show the evolution of $T$, the relative humidity over ice (RHI), and the fraction of $\mathrm{HNO}_{3}$ in the gas phase, $f\left(\mathrm{HNO}_{3}\right)$; the total mixing ratio of $\mathrm{HNO}_{3}$ is $0.5 \mathrm{ppb}$. The IN are assumed to freeze at values of RHI approximately $25 \%$ below the homogeneous freezing limit of $\sim 155 \%$, consistent with the airborne measurements (Ström et al., 2003; Haag et al., 2003b).

As cooling proceeds, the air mass becomes supersaturated and a cirrus cloud forms at $t=3 \mathrm{~h}$ around $\mathrm{RHI}=130 \%$ in the synoptic case (red curves, red arrow with label HET in the middle panel), activating all available IN $\left(0.008 \mathrm{~cm}^{-3}\right)$. When wave perturbations are allowed, a completely different cloud forms. The IN freeze earlier (at $2.2 \mathrm{~h}$, left black arrow with label HET), but later (at $3.2 \mathrm{~h}$ and $4 \mathrm{~h}$, right black arrows with label HOM) RHI achieves values high enough to freeze some of the liquid particles (in total $0.6 \mathrm{~cm}^{-3}$ ). In both cases, the ice crystals grow in the subsequent two hours. Note that the average RHI drops much faster when the rapid temperature oscillations cause the nucleation, as the time scale for depletion of available $\mathrm{H}_{2} \mathrm{O}$ vapor is inversely proportional to the number of nucleated ice crystals. Further, the buoy-

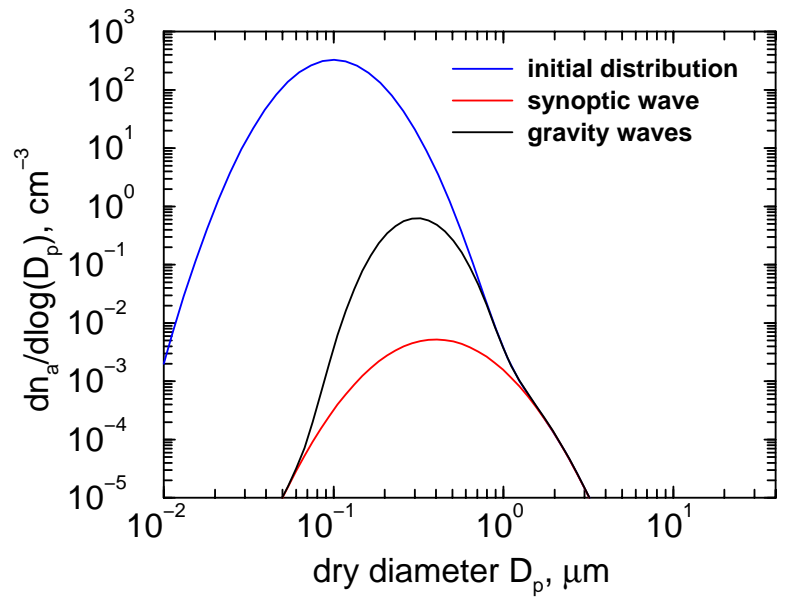

Fig. 6. Dry size distributions of freezing aerosol particles from the simulations shown in Fig. 5. The initial bimodal distribution (blue curve) is composed of liquid $\mathrm{H}_{2} \mathrm{SO}_{4} / \mathrm{H}_{2} \mathrm{O}$ droplets and heterogeneous ice nuclei. Lognormal parameters are $400 \mathrm{~cm}^{-3}, 0.05 \mu \mathrm{m}$, 1.6 (liquid aerosols) and $0.008 \mathrm{~cm}^{-3}, 0.2 \mu \mathrm{m}, 1.8$ (IN) for the total number, mode radius, and geometric width, respectively. In the synoptic case, all available IN freeze (frozen particles shown as the red curve). If synoptic cooling is perturbed by gravity waves, the IN plus a small portion of liquid particles freeze (black curve), increasing the number of ice crystals by a factor of 75 .

ancy waves cause substantial deviations (up to $25 \%$ in case of Fig. 5) of RHI from saturation, creating frequent supersaturations in cirrus. At $t=6 \mathrm{~h}$, the air mass warms synoptically, and the cloud particles start evaporating, keeping RHI between $80-100 \%$ for the next five hours. Finally, the cloud vanishes at $t=11 \mathrm{~h}$.

It is interesting to note that ice particles are preferentially formed during wave cycles with the highest cooling rates whose temperature amplitudes become sufficiently large to surpass the freezing thresholds, supporting a similar conjecture (Kärcher and Haag, 2003, their Sect. 4.4). This is an important feature to study in future work, as it may help facilitate the development of parameterizations of cirrus formation including the effect of small-scale temperature oscillations.

The initial dry aerosol size distribution is shown in Fig. 6 (blue curve). The aerosol consists of an external mixture of liquid background particles and a few IN (size parameters are given in the figure legend). The red curve is the fraction of aerosols that froze in the synoptic case. These are essentially all available IN. The black curve is the fraction of aerosols that froze in the gravity wave-perturbed case. These are all IN and a tiny fraction (about $0.5 \%$ ) of the liquid particles.

This comparison suggests that cooling rates were insufficient to trigger both, homogeneous and heterogeneous freezing modes in the synoptic case. The condensing species cannot respond immediately to the changes of RHI caused by the fast, small-scale cooling rates, producing significant departures from equilibrium. This explains why the gravity 

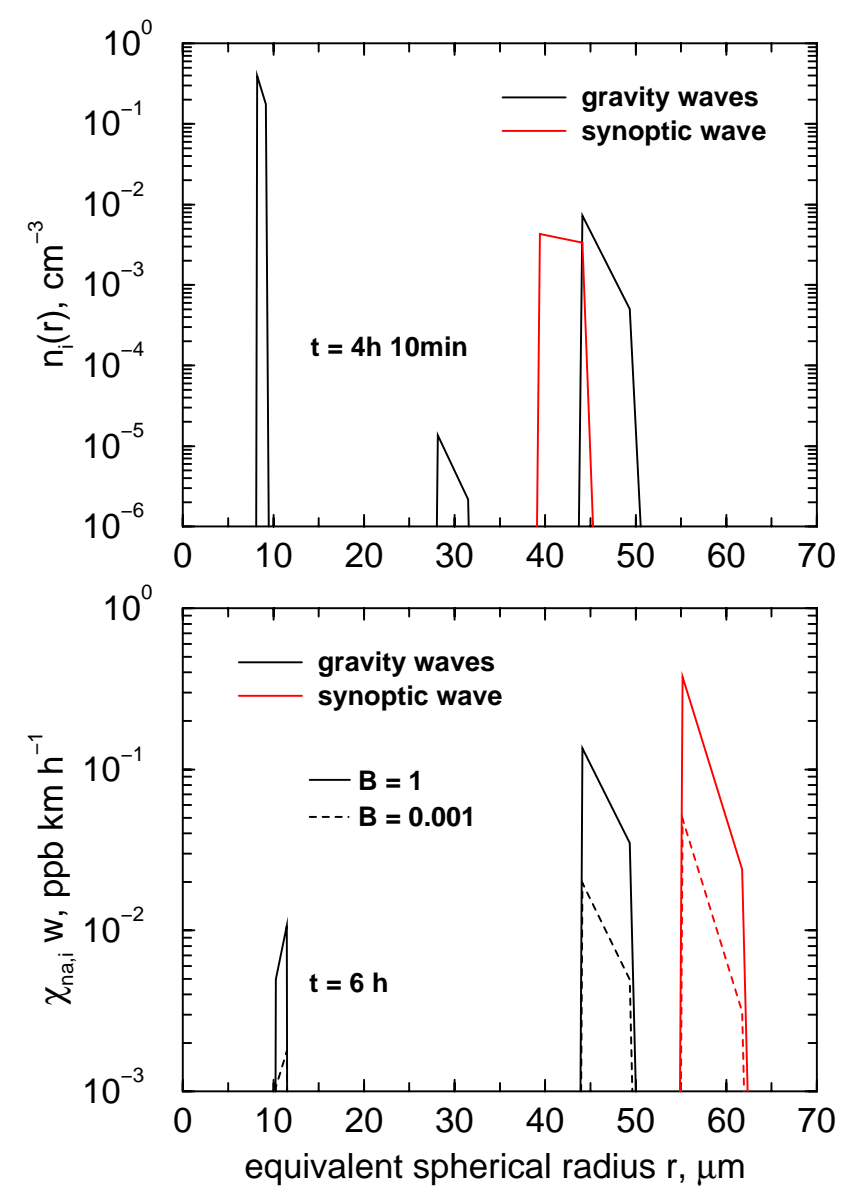

Fig. 7. Size distributions of ice crystals (top panel) and instantaneous sedimentation fluxes of $\mathrm{HNO}_{3}$ (bottom panel) for the clouds shown in Fig. 5. Ice crystals are assumed to be hexagonal columns with an aspect ratio of 3 . The length $\ell$ and diameter $d$ of the columns are related to the equivalent spherical radius via $\ell=3.87 \mathrm{r}$ and $d=1.29 r$. The total mixing ratio of $\mathrm{HNO}_{3}$ is $0.5 \mathrm{ppb}$. The black and red curves describe cirrus formed by a synoptic wave with and without superimposed gravity waves, respectively. The size distribution is shown shortly after freezing is terminated ( $t=4 \mathrm{~h} 10 \mathrm{~min}$ ). The sedimentation fluxes are shown at $6 \mathrm{~h}$ after a subsequent growth phase (note that the particle sizes have increased between 4 and $6 \mathrm{~h}$ ) and are evaluated with burial coefficients of 1 (solid curves) or 0.001 (dashed curves).

wave-driven cooling rates lead to a dramatic enhancement of the total number densities of ice crystals $n_{\mathrm{i}}$ by a factor of $0.6 / 0.008=75$. On the other hand, under the assumption of a constant cooling rate, Kärcher and Lohmann (2003) have shown that the addition of a few externally mixed, efficient IN could promote the suppression of $n_{\mathrm{i}}$, the effectiveness of ice crystal reduction depending on the cooling rate (i.e., vertical wind speed), temperature, and IN properties. As suggested in Figs. 5 and 6, the presence of mesoscale temperature fluctuations renders a sound assessment of the indirect aerosol effect on cirrus considerably more difficult as IN and waves may compete with each other in changing basic cirrus properties.

Ice crystal size distributions shortly after freezing for the wave clouds discussed above are depicted in Fig. 7 (top panel). While only one mode of large crystals forms on IN in the synoptic wave (40-45 $\mu \mathrm{m}$, red curve), three modes are observed in the case of buoyancy wave-driven cooling (black curves). The rightmost mode at 45-50 $\mu \mathrm{m}$ stems from the IN, as for synoptic cooling. Particles in this mode have grown to the largest sizes because they were formed earliest (middle panel in Fig. 5). The two other modes at $\sim 8 \mu \mathrm{m}$ and $\sim 30 \mu \mathrm{m}$ are formed homogeneously in two small-scale wave events between $3-4 \mathrm{~h}$.

It has been shown earlier that bimodal size distributions can be caused by the combination of waves and homogeneous freezing (Lin et al., 1998). The simulations presented in this work demonstrate that the modal size structure of cirrus particles can become even more complex when heterogeneous freezing processes additionally come into play. While the total ice crystal number density in thin cirrus is likely to be controlled by homogeneous nucleation, crystals with largest dimensions in the range $50-100 \mu \mathrm{m}$ observed in thin cirrus near the tropical tropopause (Heymsfield, 1986) are likely to be formed on a few efficient IN as proposed here.

Another process that can lead to multimodal size distributions is sedimentation. The different crystal sizes imply that the mode containing the largest particles will preferentially contribute to sedimentation. In both, synoptic and gravitywave cases, the crystals that fall at the fastest rate formed heterogeneously and hence cause a vertical redistribution of IN. This may eventually leed to the seeding of ice in lower level, mixed phase clouds.

Figure 7 indicates differences in the width of the ice crystal modes. They are narrower for the small particle mode than for the larger modes. The size distributions become broader when the time scale of depositional growth of the fresh ice crystals is comparable with, or shorter than, the time scale of the freezing event. How effective the broadening can be depends on the cooling rate, the temperature, and the size of the freezing particles, which determine these time scales (Bell and Ford, 2000; Kärcher and Lohmann, 2002).

In the simulations, we assume that the cirrus particles can interact with $\mathrm{HNO}_{3}$. The retention coefficient $R$ is set equal to unity. Varying $R$ has little effect on the evolution of the gas phase fraction of $\mathrm{HNO}_{3}$ shown in the bottom panel of Fig. 5, but the results are sensitive to the burial coefficient $B$. Two cases are discussed: complete ( $B=1$, solid curves) and incomplete ( $B=0.001$, dashed curves) trapping in growing ice particles. In the first two hours of cooling, $f\left(\mathrm{HNO}_{3}\right)$ is reduced because nitric acid dissolves in the liquid particles. When ice forms, $f\left(\mathrm{HNO}_{3}\right)$ is reduced further because the molecules are being trapped in the growing crystals. A marked difference develops between complete and incomplete burial after the ice particle growth phase. Upon 
evaporation of the clouds, all trapped $\mathrm{HNO}_{3}$ molecules return to the gas phase.

In the case of small-scale waves, the rapid cooling and warming cycles near ice saturation produce a complex pattern of $f\left(\mathrm{HNO}_{3}\right)$ owing to rapid co-condensation and coevaporation of $\mathrm{HNO}_{3}$ along with $\mathrm{H}_{2} \mathrm{O}$. Irrespective of the chosen value for $B$, this discussion emphasizes the difficulty to interpret airborne measurements of $\mathrm{HNO}_{3}$ uptake on cirrus cloud particles.

Denitrification of air masses may occur through sedimenting ice crystals that contain $\mathrm{HNO}_{3}$. The denitrification process is very difficult to describe, as it involves uptake of $\mathrm{HNO}_{3}$ on ice crystals formed at different times, with different concentrations and growing at different rates, hence falling with different velocties in air masses that may be sub- or supersaturated with respect to ice. In Fig. 7 (bottom panel), the instantaneous vertical flux of $\mathrm{HNO}_{3}$ contained in cloud ice is plotted as a function of crystal size at $t=6 \mathrm{~h}$ for the two dynamical scenarios and two burial coefficients consistent with Fig. 5 (bottom panel). The flux is obtained by multiplying $c_{\mathrm{na}, \mathrm{i}}$ (expressed as a volume mixing ratio) by the crystal terminal fall speed $w$. Note that the ice mode formed in the synoptic case has grown to $60 \mu \mathrm{m}$ at $6 \mathrm{~h}$ (red curves); these ice crystals became larger than those formed formed on IN in the mesoscale gravity wave case (rightmost black curves) owing to their lower number density and the lack of many small particles.

As expected, the vertical flux of $\mathrm{HNO}_{3}$ is larger the higher $B$. Owing to the relatively small fall speeds, the ice mode near $10 \mu \mathrm{m}$ associated with the strongest homogeneous freezing event exhibits only a small contribution to the total flux (less than 10\%). The number density of the intermediate mode near $30 \mu \mathrm{m}$, also caused by homogeneous nucleation, is too low to significantly affect $f\left(\mathrm{HNO}_{3}\right)$ (not visible in the bottom panel of Fig. 7). Only the modes formed on IN have the potential to denitrify the cloud formation layer, with fluxes reaching up to $0.15-0.4 \mathrm{ppb} \mathrm{km} \mathrm{h}^{-1}$ for $B=1$. These numbers indicate that almost complete removal of the nitric acid reservoir is possible on the time scale of $1-2 \mathrm{~h}$, with potential implications for the chemistry of ozone in the UTLS region (Meilinger et al., 2001; Meier and Hendricks, 2002). Clearly, it is highly desirable to better constrain the value of burial coefficient for $\mathrm{HNO}_{3}$.

\subsection{Numerical solutions}

Changes of number of mass concentrations caused by air motion are computed directly from the pressure and temperature changes after each time step $\Delta t$, using the ideal gas law. The mixing Eq. (3) is solved using Euler backward (implicit) time stepping, assuming that the mixing rate $\omega$ does not significantly change in this time interval. An exact analytical solution is possible if the dilution factor $\int_{t}^{t+\Delta t} \omega\left(t^{\prime}\right) d t^{\prime}$ can be calculated explicity. Phase transitions are handled by integrating the nucleation Eqs. (4) (binary homogeneous nucle- ation equation for $n_{l}$ ), (5) (freezing equation for $n_{\mathrm{a}}$ ), and (6) (gas retention equation for $c_{l, \mathrm{a}}$ ) over one time step; the differences are then added to the concentrations of the nucleated phases to ensure overall mass conservation of each type of molecule and the total number of (aerosol and ice) particles.

The growth Eqs. (8), (13), (15), and (22) are coupled to the gas phase and solved using the analytical predictor schemes for dissolution and condensation, as proposed by Jacobson (1999). These schemes are non-iterative, unconditionally stable, and mass-conserving. The coagulation Eq. (14) over two particle size distributions with multiple chemical components are solved using the semi-implicit coagulation solution described by Jacobson (1999). This computationally efficient scheme conserves particle volume exactly and is stable.

If the relative humidity falls below a given threshold, water may be instantaneously equilibrated with the liquid aerosol particles (recall Sect. 2.5). This is accomplished by solving the nonlinear equations $n_{\mathrm{wv}}=K_{\mathrm{wv}, \mathrm{a}} e_{\mathrm{wv}, \mathrm{a}}$ iteratively for the mass fractions of water in liquid aerosol particles $c_{\mathrm{wv}, \mathrm{a}}$, using a bisection method. This is done for each radius bin after the mass fractions of all other aerosol components $c_{l, \text { a }}$ have been determined with the help of the nucleation/dissolution/condensation equations.

\section{Possible model extensions}

It may be necessary to modify the APSC/APSC $m$ in order to treat problems not covered by the present versions and to be prepared for new challenges. Potential changes of or additions to the code include: (i) updated heterogeneous nucleation rates, including experimental data on IN freezing thresholds; (ii) nucleation and growth of nitric acid trihydrate (NAT) on ice crystals; (iii) physical models for the burial coefficient and gas retention; (iv) a kinetic model to compute the coverage of trace gases on static ice surfaces; (v) other chemical compositions of liquid aerosol particles, such as aqueous organic solutions or ammoniated sulfates, including ternary nucleation rates for the $\mathrm{H}_{2} \mathrm{O} / \mathrm{H}_{2} \mathrm{SO}_{4} / \mathrm{NH}_{3}$ system.

As for point (i), new laboratory information is becoming available for freezing of insoluble nuclei relevant to the UTLS, such as mineral dust and black carbon (see references compiled in Kärcher and Lohmann, 2003). The implementation of NAT particle growth (point ii) is possible as their equilibrium properties are well known (Hanson and Mauersberger, 1988), however, it is still uncertain how NAT nucleates on ice particles (Luo etal., 2003). Current laboratory and field data are insufficient to constrain possible models for $B_{l}$ and $R_{l}$ (point iii) and infer desorption rates (point iv) that would enable a kinetic description of interactions of cirrus particles with, for instance, $\mathrm{HNO}_{3}$. Parameterization schemes for the equilibrium vapor pressures of fully liquid ammoniated sulfate particles (Lin and Tabazadeh, 2001) and ternary nucleation rates (Korhonen et al., 1999; Hanna Vehkamäki, personal communication, 


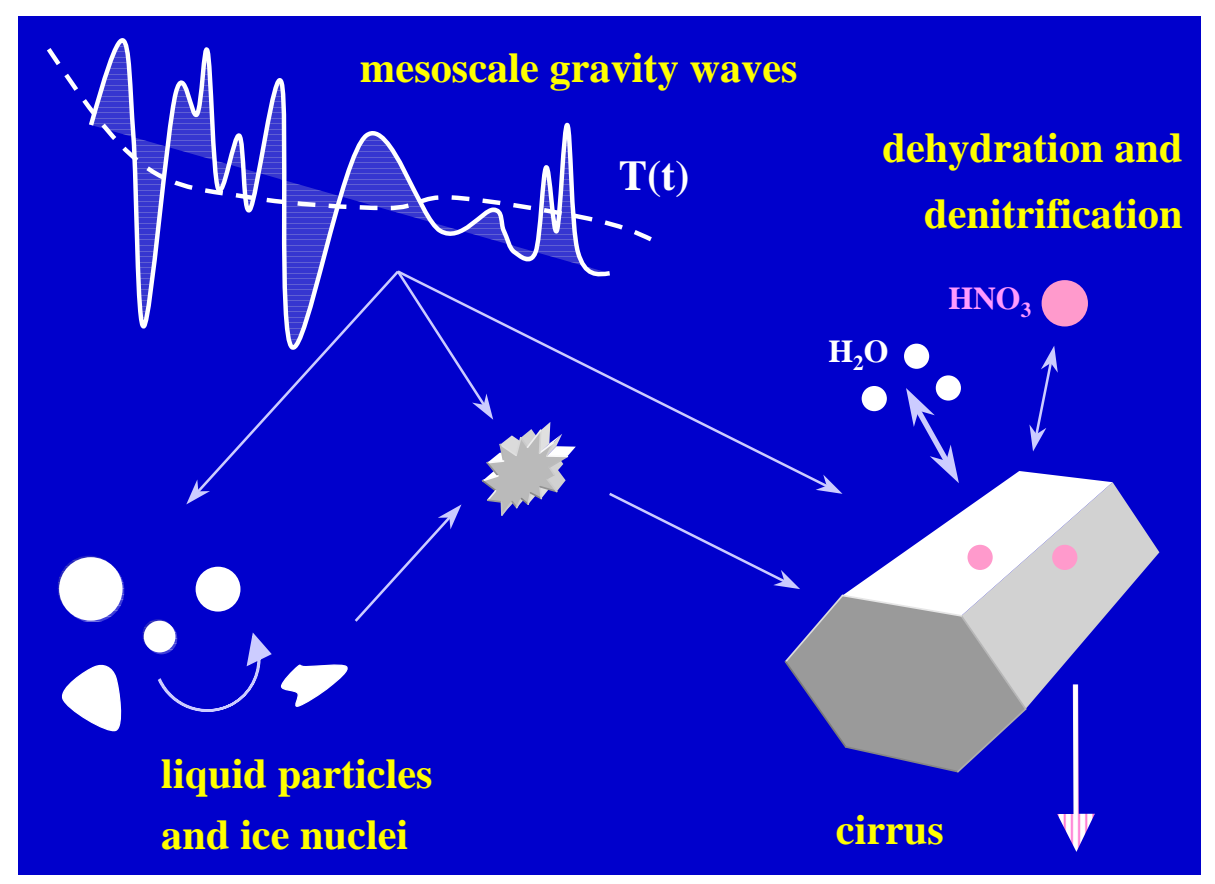

Fig. 8. Schematic illustrating some gas-aerosol-cirrus cloud processes in the UTLS region as examined in the present work, affecting the radiation budget and the chemistry of ozone in this part of the atmosphere. The indirect effect of aerosols on cirrus clouds will be strongly influenced by competition between liquid particles and one or several types of ice nuclei for the available water during the freezing process. Uptake of $\mathrm{H}_{2} \mathrm{O}$ on cirrus ice crystals controls in part the efficiency of dehydration of air entering the tropical stratosphere and thus the stratospheric water budget. Uptake of $\mathrm{HNO}_{3}$ on cirrus ice crystals may lead to denitrification possibly affecting the net production rate of ozone. Vertical redistribution of efficient ice nuclei by sedimentation of ice crystals that have formed on those aerosol particles may initiiate the ice phase in supercooled clouds present at altitudes below the cirrus levels. Ubiquitous small-scale gravity waves tied to convection, turbulence, and orographic forcings, will exert a strong influence on freezing, growth, sedimentation, dehydration, and denitrification. All of these processes shown are complex and will require an extraordinary effort to understand in detail.

2002) are available (point $v$ ), but the nucleation rates are not validated for $T<240 \mathrm{~K}$ and the use of liquid phase thermodynamics is complicated by the fact that these particles likely undergo frequent phase transitions (crystallization and deliquescence) in the upper troposphere (Colberg et al., 2003).

In the future, the APSC $m$ will be extended to a onedimensional column model including sedimentation of ice crystals. Such a model version allows us to study and predict dehydration and denitrification of air masses at the tropopause by a single cloud pass, and to interprete field data more realistically.

\section{Conclusions}

An innovative process model for UTLS research, the APSC, has been described in this paper. This microphysicalchemical simulation tool describes aqueous supercooled solution droplets consisting of $\mathrm{H}_{2} \mathrm{SO}_{4}, \mathrm{HNO}_{3}, \mathrm{HCl}$, and $\mathrm{HBr}$ along with insoluble inclusions. The liquid particles may form from the gas phase via binary nucleation of $\mathrm{H}_{2} \mathrm{SO}_{4}$ and $\mathrm{H}_{2} \mathrm{O}$. This internal aerosol mixture can form ice particles by homogeneous and heterogeneous freezing nucleation. Other microphysical processes include condensation, dissolution, coagulation, deposition, gas retention, gas trapping in growing ice particles, and the respective reverse processes. A simple gas phase chemistry is included to calculate the chemical production of $\mathrm{H}_{2} \mathrm{SO}_{4}$ via oxidation of $\mathrm{SO}_{2}$. Aerosol particles may be equilibrated with ambient $\mathrm{H}_{2} \mathrm{O}$ at low relative humidities. There are various options to discretize the particles into size bins and to treat nucleation, growth, and coagulation. Effects of dynamical mixing can also be treated.

In a second version of the code, the APSC $m$, binary nucleation and coagulation is not included, but liquid particles along with any number $N$ of insoluble particles can freeze as external mixtures to produce $N+1$ distinct ice modes. This feature is required to simulate competition among multiple freezing particle types, an essential prerequisite to study potential indirect aerosol effects on cirrus clouds.

By comparison with other models and with in situ measurements, it has been shown that the APSC/APSC $m$ can provide accurate predictions of atmospheric phenomena relevant to UTLS research, including the formation and growth of 
aerosols, cirrus clouds, and polar stratospheric clouds. Some applications of earlier versions of the APSC have already been documented (Lin et al., 2002; Kärcher and Lohmann, 2002; Haag et al., 2003a; Kärcher and Lohmann, 2003). Possible model extensions have been proposed in the present work, part of which require more experimental information to constrain open parameters.

Along with the description of model equations and numerical solution schemes, the present study discusses atmospheric applications of the APSC such as the formation of aerosols and liquid-phase PSCs. Most importantly, the formation of cirrus clouds in synoptic and mesoscale waveinduced cooling events has been examined, with inferences for the indirect effect of ice nuclei on cirrus and the vertical redistribution of $\mathrm{H}_{2} \mathrm{O}, \mathrm{HNO}_{3}$, and ice nuclei. A summary of these processes is provided by Fig. 8 .

The discussion of cirrus simulations highlights the importance of buoyancy waves causing rapid temperature oscillations and heterogeneous ice nuclei on both, the formation and evolution of cirrus ice crystals and dehydration and denitrification processes in the UTLS region. As indicated in Fig. 8, these processes are strongly linked to each other. The efficiency of each process depends on wave properties (amplitudes, frequencies), concentrations of heterogeneous ice nuclei and their freezing threshold relative humidities, among other factors.

Ice crystal size distributions, the creation, extent, and maintenance of ice supersaturation inside and outside of cirrus clouds, and the scavenging of trace gases such as $\mathrm{HNO}_{3}$ is controlled by the interaction of waves, freezing, and ice particle growth and sedimentation. Amplitudes (up to $2 \mathrm{~K}$ ) and frequencies $20 \pm 10 \mathrm{~min}$ of mesoscale temperature fluctuations can affect the nucleation of cirrus particles and produce significant departures from equilibrium in thin (subvisual) cirrus with regard to the uptake of $\mathrm{HNO}_{3}$ and even $\mathrm{H}_{2} \mathrm{O}$. Homogeneous nucleation may dominate the total ice crystal number density (and probably the effective radius) in most cases, but heterogeneous ice nuclei can potentially modify those details of the cloud microphysics which are essential for dehydration and denitrification processes. The presence of a few efficient ice nuclei may lead to multimodal ice particle size distributions by the generation of large $(50-100 \mu \mathrm{m})$ particles quickly sedimenting out of the formation layer.

The example simulations discussed in the present work are not meant to be complete. Rather, it is intended to highlight the potential importance of heterogeneous ice nuclei and mesoscale dynamical variability in cooling rates and to stimulate detailed experimental and numerical studies constraining the uncertainties associated with the calculations.

\section{Notation}

$a_{w} \quad$ water activity

$c$ number density in the particle phase

$d$ diameter of column

$e \quad$ equilibrium (saturation) number density

$j$ nucleation rate

$k \quad$ kinetic prefactor

$m$ particle mass

$n \quad$ gas phase or particle number density

$p \quad$ air pressure

$r$ particle radius

$\bar{v} \quad$ mean thermal speed of a molecule

$w \quad$ ice crystal terminal fall speed

$A$ particle surface area density

$B$ burial coefficient

C coagulation rate coefficient

$D$ diffusion coefficient of molecules in air

$D_{p}$ particle diameter

$H$ effective solubility

$J \quad$ nucleation rate coefficient

$K \quad$ Kelvin barrier

$R \quad$ retention coefficient

$T$ air temperature

$V$ particle volume density

$W$ mass fraction

$\mathrm{Be} \quad$ Best number

Kn Knudsen number

Re Reynolds number

Sc Schmidt number

$\mathcal{A} \quad$ aspect ratio

$\mathcal{N}$ number of molecules in a critical germ

$\mathcal{V} \quad$ average total volume of a particle

$\alpha \quad$ mass accomodation or deposition coefficient

$\beta \quad$ transitional correction factor

$\gamma \quad$ adiabatic coefficient

$\kappa \quad$ capacitance

$\lambda \quad$ molecular mean free path

$\eta \quad$ dynamic viscosity of air

$v \quad$ molecular volume

$\phi \quad$ ventilation factor

$\rho \quad$ mass density of air

$\chi \quad$ volume mixing ratio

$\omega \quad$ mixing rate

subscripts

$j \quad$ summation index for size bins

$k \quad$ summation index for particles

$l \quad$ summation index for molecular species

a aerosol particle

i ice crystal

$\mathrm{t}$ total (gas and particle phase)

wV water vapor

na nitric acid

sa sulfuric acid

amb ambient 

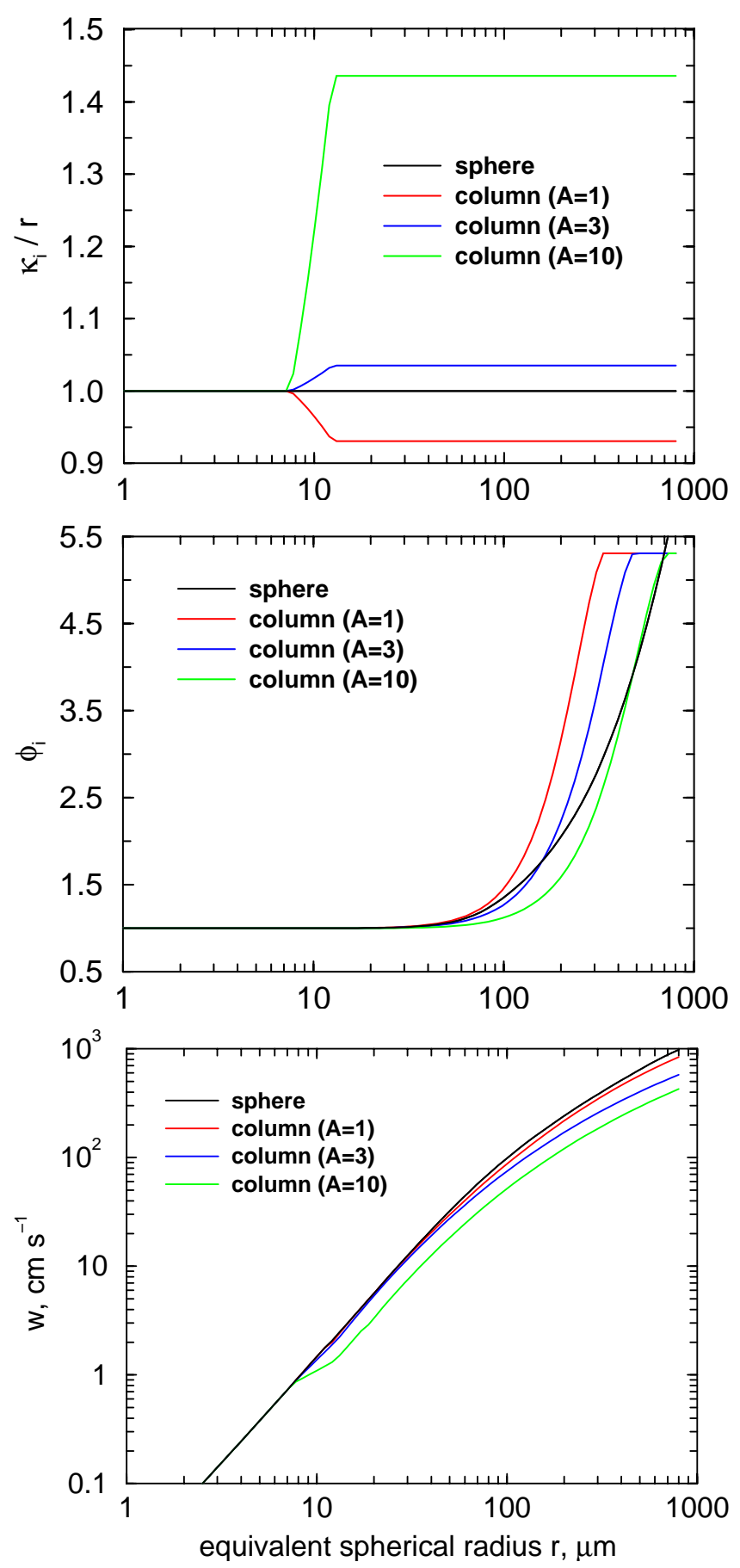

Fig. 9. Capacity factor $\kappa_{\mathrm{i}} / r$, ventilation factor $\phi_{\mathrm{i}}$, and terminal fall velocity $w$ of ice crystals of various shapes (spheres and hexagonal columns with aspect ratios $\mathcal{A}=1 \cdots 10$ ) as a function of the radius $r$ of a volume-equivalent sphere. Ice crystals below $7.5 \mu \mathrm{m}$ are always spherical and assume their prescribed columnar shapes above $12.5 \mu \mathrm{m}$. Values at intermediate radii are obtained by linear interpolation.

\section{Appendix: Properties of cirrus ice crystals}

The normalized capacitance, ventilation coefficient, and sedimentation velocity of ice crystals are plotted as a function of the radius of a volume-equivalent sphere in Fig. 9. Black curves are computed for spherical particles and colored curves for hexagonal columns with various aspect ratios $\mathcal{A}$, as described in Sect. 3.5.

The growth rate of ice crystals is changed by less than $10 \%$ unless the aspect ratio exceeds 3. Enhanced growth due to ventilation effects only becomes important for particles with $r>40 \mu \mathrm{m}$ for all shapes, leading to substantial enhancements if crystals grow past $100 \mu \mathrm{m}$. Note that we have cut-off $\phi_{\mathrm{i}}$ for the largest sizes as the relationship for columns provided by Pruppacher and Klett (1997) becomes invalid. Terminal fall speeds increase with size $\left(w \propto r^{a}, a=1-2\right.$ for particles in the Cunningham, Stokes, and Oseen-Best regime), but become relevant only for particles $>10 \mu \mathrm{m}$ in radius, where also shape effects become important. The fall speed $1 \mathrm{~cm} \mathrm{~s}^{-1}$ corresponds to the time $10^{5} \mathrm{~s}$ required to fall through a $1 \mathrm{~km}$ thick layer.

In summary, the differences between spheres and hexagonal columns with $\mathcal{A}=1 \cdots 3$ are small (growth rates and sedimentation speeds change within a factor of two). For columns of fixed size, the normalized capacitance increases, the ventilation factor decreases, and the sedimentation velocity decreases when $\mathcal{A}$ increases.

Acknowledgements. I am grateful to K. Carslaw, I. Ford, W. Haag, M. Jacobson, N. Larsen, B. Luo, S. Meilinger, H. Vehkamäki, and F. Yu for many helpful discussions. This work contributes to the project "Particles and Cirrus Clouds" (PAZI) supported by the Helmholtz-Gemeinschaft Deutscher Forschungszentren (HGF).

\section{References}

Bell, K. and Ford, I. J.: Criteria for broadening size distributions due to cooling and freezing of a water aerosol, J. Aerosol Sci., 31, S799-S800, 2000.

Binkowski, F. S. and Shankar, U.: The regional particulate model, 1. Model description and preliminary results, J. Geophys. Res., 100, 26 191-26 209, 1995.

Clement, C. F. and Ford, I. J.: Gas-to-particle conversion in the atmosphere: II. Analytical models of nucleation bursts, Atmos. Environ., 33, 489-499, 1999.

Clement, C. F., Ford, I. J., Twohy, C. H., Weinheimer, A., and Campos, T.: Particle production in the outflow of a mid-latitude storm, J. Geophys. Res., 107, 4559, doi:10.1029/2001JD001352, 2002.

Colberg, C., Luo, B. P., Wernli, H., Koop, T., and Peter, Th.: A novel model to predict the physical state of atmospheric $\mathrm{H}_{2} \mathrm{SO}_{4} / \mathrm{NH}_{3} / \mathrm{H}_{2} \mathrm{O}$ aerosol particles, Atmos. Chem. Phys., 3, 909-924, 2003.

CORSAIRE, Coordination of Research for the Study of Aircraft Impact on the Environment, http://www.ozone-sec.ch.cam.ac.uk, 2003. 
de Reus, M., Ström, J., Kulmala, M., Pirjola, L., Lelieveld, J., Schiller, C., and Zöger, M.: Airborne aerosol measurements in the tropopause region and the dependence of new particle formation on preexisting particle number concentration, J. Geophys. Res., 103, 31 255-31 263, 1998.

de Reus, M., Ström, J., Curtius, J., Pirjola, L., Vignati, E., Arnold, F., Hansson, H. C., Kulmala, M., Lelieveld, J., and Raes, F.: Aerosol production and growth in the upper free troposphere, J. Geophys. Res., 105, 24 751-24 762, 2000.

Fahey, D. W., Gao, R. S., Carslaw, K. S., Kettleborough, J., Popp, P. J., Northway, M. J., Holecek, J. C., Ciciora, S. C., McLaughlin, R. J., Thompson, T. L., Winkler, R. H., Baumgardner, D. G., Gandrud, B., Wennberg, P. O., Dhaniyala, S., McKinney, K., Peter, Th., Salawitch, R. J., Bui, T. P., Elkins, J. W., Webster, C. R., Atlas, E. L., Jost, H., Wilson, J. C., Herman, R. L., Kleinböhl, A., and von König, M.: The detection of large $\mathrm{HNO}_{3}$-containing particles in the winter Arctic Stratosphere, Science, 291, 10261031, 2001.

Friedl, R. R. (Ed): Atmospheric Effects of Subsonic Aircraft: Interim Assessment Report of the Advanced Subsonic Technology Program, NASA Reference Publication 1400, May, 1997.

Goodman, J., Toon, O. B., Pueschel, R. F., Snetsinger, K. G., and Verma, S.: Antarctic stratospheric ice crystals, J. Geophys. Res., 94, 16449-16457, 1989.

Haag, W., Kärcher, B., Schaefers, S., Stetzer, O., Möhler, O., Schurath, U., Krämer, M., and Schiller, C.: Numerical simulations of homogeneous freezing processes in the aerosol chamber AIDA, Atmos. Chem. Phys., 3, 195-210, 2003 a.

Haag, W., Kärcher, B., Ström, J., Minikin, A., Lohmann, U., Ovarlez, J., and Stohl, A.: Freezing thresholds and cirrus cloud formation mechanisms inferred from in situ measurements of relative humidity, Atmos. Chem. Phys., 3, in press, 2003b.

Hanson, D., and Mauersberger, K.: Laboratory studies of the nitric acid trihydrate: Implications for the south polar stratosphere, Geophys. Res. Lett., 15, 855-858, 1988.

Haynes, D. R., Tro, N. J., and George, S. M.: Condensation and evaporation of $\mathrm{H}_{2} \mathrm{O}$ on ice surfaces, J. Phys. Chem., 96, 85028509, 1992.

Heymsfield, A. J.: Ice particles observed in a cirriform cloud at $-83^{\circ} \mathrm{C}$ and implications for polar stratospheric clouds, J. Atmos. Sci., 43, 851-855, 1986.

IGAC, International Global Atmospheric Chemistry Project, International Geosphere-Biosphere Program, http://www.igac.unh. edu, 2003.

Jacobson, M. Z.: Fundamentals of Atmospheric Modeling, Cambridge Univ. Press, Cambridge, UK, 1999.

Kärcher, B. and Solomon, S.: On the composition and optical extinction of particles in the tropopause region, J. Geophys. Res., 104, 27 441-27 459, 1999.

Kärcher, B. and Lohmann, U.: A parameterization of cirrus cloud formation: Homogeneous freezing including effects of aerosol size, J. Geophys. Res., 107, 4698, doi:10.1029/2001JD001429, 2002.

Kärcher, B. and Lohmann, U.: A parameterization of cirrus cloud formation: Heterogeneous freezing, J. Geophys. Res., 108, 4402, doi:10.1029/2002JD003220, 2003.

Kärcher, B. and Ström, J.: The roles of dynamical variability and aerosols in cirrus cloud formation, Atmos. Chem. Phys., 3, 823838, 2003.
Kärcher, B. and Haag, W.: Factors controlling upper tropospheric relative humidity, Ann. Geophys., 21, in press, 2003.

Kawa, S. R. (Assessment Chair): Assessment of the Effects of High-Speed Aircraft in the Stratosphere: 1998, NASA Technical Publication 1999-209237, June, 1999.

Kerminen, V.-M., Pirjola, L., and Kulmala, M.: How significantly does coagulational scavenging limit atmospheric particle production ?, J. Geophys. Res., 106, 24 119-24 125, 2001.

Korhonen, P., Kulmala, M., Laaksonen, A., Viisanen, Y., McGraw, R., and Seinfeld, J. H.: Ternary nucleation of $\mathrm{H}_{2} \mathrm{SO}_{4}, \mathrm{NH}_{3}$, and $\mathrm{H}_{2} \mathrm{O}$ in the atmosphere, J. Geophys. Res., 104, 26349-26353, 1999.

Koop, T., Luo, B.P., Tsias, A., and Peter, Th.: Water activity as the determinant for homogeneous ice nucleation in aqueous solutions, Nature, 406, 611-614, 2000.

Korolev, A. and Isaac, G.: Roundness and aspect ratio of particles in ice clouds, J. Atmos. Sci., 60, 1795-1808, 2003.

Larsen, N.: Polar stratospheric clouds - Microphysical and optical models, Danish Meteorological Institute, Report 00-06, ISSN 0905-3263, Copenhagen, 2000.

Lin, H., Noone, K. J., Ström, J., and Heymsfield, A. J.: Dynamical influences on cirrus cloud formation processes, J. Atmos. Sci., 55, 1940-1949, 1998.

Lin, J.-S. and Tabazadeh, A.: A parameterization of an aerosol physical chemistry model for the $\mathrm{NH}_{3} / \mathrm{H}_{2} \mathrm{SO}_{4} / \mathrm{HNO}_{3} / \mathrm{H}_{2} \mathrm{O}$ system at cold temperatures, J. Geophys. Res., 106, 4815-4829, 2001.

Lin, R.-F., Starr, D. O’C., DeMott, P. J., Cotton, R., Sassen, K., Jensen, E., Kärcher, B., and Liu, X.: Cirrus parcel model comparison project phase 1: The critical components to simulate cirrus initiation explicity, J. Atmos. Sci., 59, 2305-2329, 2002.

Lowe, D., MacKenzie, A. R., Nikiforakis, N., and Kettleborough, $\mathrm{J}$.: A condensed-mass advection based model for the simulation of liquid polar stratospheric clouds, Atmos. Chem. Phys., 3, 2938, 2003.

Luo, B. P., Carslaw, K. S., Peter, Th., and Clegg, S. L.: Vapour pressures of $\mathrm{H}_{2} \mathrm{SO}_{4} / \mathrm{HNO}_{3} / \mathrm{HCl} / \mathrm{HBr} / \mathrm{H}_{2} \mathrm{O}$ solutions to low stratospheric temperatures, Geophys. Res. Lett., 22, 247-250, 1995.

Luo, B. P., Voigt, C., Fueglistaler, S., and Peter, Th.: Extreme NAT supersaturations in mountain wave ice PSCs a clue to NAT formation, J. Geophys. Res., 108, 4441, doi:10.1029/2002JD003104, 2003.

Marti, J. and Mauersberger, K.: A survey and new measurements of ice vapor pressure at temperatures between 170 and $250 \mathrm{~K}$, Geophys. Res. Lett., 20, 363-366, 1993.

Meier, A. and Hendricks, J.: Model studies on the sensitivity of upper tropospheric chemistry to heterogeneous uptake of $\mathrm{HNO}_{3}$ on cirrus ice particles, J. Geophys. Res., 107, 4696, doi:10.1029/2001JD000735, 2002.

Meilinger, S. K.: Non-equilibrium liquid stratospheric aerosols, Diploma Thesis, Johannes Gutenberg Universität, Mainz, 1995.

Meilinger, S. K., Koop, T., Luo, B. P., Huthwelker, T., Carslaw, K. S., Krieger, U., Crutzen, P. J., and Peter, Th.: Size-dependent stratospheric droplet composition in mesoscale temperature fluctuations and their potential role in PSC freezing, Geophys. Res. Lett., 22, 3031-3034, 1995.

Meilinger, S. K., Kärcher, B., and Peter, Th.: On the impact of heterogeneous chemistry on ozone in the tropopause region, Geophys. Res. Lett., 28, 515-518, 2001. 
Miloshevich, L. M. and Heymsfield, A. J.: A balloon-borne continuous cloud particle replicator for measuring vertical profiles of cloud microphysical properties: Instrument design, performance, and collection efficiency analysis, J. Atmos. Oceanic Technol., 14, 753-768, 1997.

Murphy, D. M. and Gary, B. L.: Mesoscale temperature fluctuations and polar stratospheric clouds, J. Atmos. Sci., 52, 1753-1760, 1995.

Murphy, D. M., Thomson. D. S., and Mahoney, M. J.: Organics, meteoritic material, mercury, and other elements in high altitude aerosols, Science, 282, 1664-1669, 1998.

Oran, E. S. and Boris, J. P.: Numerical Simulation of Reactive Flow, Elsevier Sci., New York, 1987.

Peter, Th., Luo, B. P., Wernli, H., Wirth, M., Kiemle, C., Flentje, H., Yushkov, V. A., Khattatov, V., Rudakov, V., Thomas, A., Borrmann, S., Toci, G., Mazzinghi, P., Beuermann, J., Schiller, C., Cairo, F., Di Donfrancesco, G., Adriani, A., Volk, C. M., Ström, J., Noone, K., Mitev, V., MacKenzie, R. A., Carslaw, K. S., Trautmann, T., Santacesaria, V., and Stefanutti, L.: Ultrathin tropical tropopause clouds (UTTCs): I. Cloud morphology and occurrence, Atmos. Chem. Phys., 3, 1093-1100, 2003.

Pirjola, L. and Kulmala, M.: Development of particle size and composition distributions with a novel aerosol dynamics model, Tellus, 53B, 491-509, 2001.

Pruppacher, H. R. and Klett, J. D.: Microphysics of Clouds and Precipitation, Kluwer Acad. Pub., Dordrecht, 1997.

Reiner, T. and Arnold, F.: Laboratory flow reactor measurements of the reaction $\mathrm{SO}_{3}+\mathrm{H}_{2} \mathrm{O}+\mathrm{M} \rightarrow \mathrm{H}_{2} \mathrm{SO}_{4}+\mathrm{M}$ : Implications for gaseous $\mathrm{H}_{2} \mathrm{SO}_{4}$ and aerosol formation in the plumes of jet aircraft, Geophys. Res. Lett., 20, 2659-2662, 1993.

Schröder, F., Kärcher, B., Duroure, C., Ström, J., Petzold, A., Gayet, J.-F., Strauss, B., Wendling, P., and Borrmann, S.: The transition of contrails into cirrus clouds, J. Atmos. Sci., 57, 464-480, 2000.

SPARC, Stratospheric Processes and Their Role in Climate, World Climate Research Program, http://www.aero.jussieu.fr/ $\sim_{\text {sparc, }}$ 2003.

Ström, J., Seifert, M., Kärcher, B., Ovarlez, J., Minikin, A., Gayet, J.-F., Krejci, R., Petzold, A., Auriol, F., Busen, R., Schumann, U., Haag, W., and Hansson, H. C.: Cirrus cloud occurrence as a function of ambient relative humidity: A comparison of observations obtained during the INCA experiment, Atmos. Chem. Phys., 3, in press, 2003.
Stockwell, W. R. and Calvert, J. G.: The mechanism of the $\mathrm{HO}-\mathrm{SO}_{2}$ reaction, Atmos. Environ., 17, 2231-2235, 1983.

Toon, O. B. and Ackerman, T.: Algorithms for the calculation of scattering by stratified spheres, Appl. Opt., 20, 3657-3660, 1981.

Toon, O. B., Turco, R. P., Westphal, D., Malone, R., and Liu, M. S.: A multidimensional model for aerosols: Description of computational analogs, J. Atmos. Sci., 45, 2123-2143, 1988.

Toon, O. B., Turco, R. P., Jordan, J., Goodman, J., and Ferry, G.: Physical processes in polar stratospheric ice clouds, J. Geophys. Res., 94, 11359-11380, 1989.

Turco, R. P., Hamill, P., Toon, O. B., Whitten, R. C., and Kiang, C. S.: The NASA Ames Research Center Stratospheric Aerosol Model, I. Physical Processes and Computational Analogs, NASA Technical Paper 1362, April, 1979.

Turco, R. P., Toon, O. B., Whitten, R. C., Keesee, R. G., and Hollenbach, D.: Noctilucent clouds: Simulation studies of their genesis, properties and global influences, Planet. Space Sci., 30, 1147$1181,1982$.

Twohy, C. H., Clement, C. F., Gandrud, B. W., Weinheimer, A., Campos, T., Baumgardner, D., Brune, W. H., Faloona, I., Tan, D., Sachse, G. W., Vay, S. A., and Tan, D.: Deep convection as a source of new particles in the midlatitude upper troposphere, J. Geophys. Res., 107, 4560, doi:10.1029/2001JD000323, 2002.

Wang, P. K.: Ice Microdynamics, Academic Press, Elsevier Sci., San Diego, 2002.

Warshawsky, M. S., Zondlo, M. A., and Tolbert, M. A.: Impact of nitric acid on ice evaporation rates, Geophys. Res. Lett., 26, 823-826, 1999.

Wiscombe, W. J.: Improved Mie scattering algorithms, Appl. Opt., 19, 1505-1509, 1980.

Wofsy, S. C., Salawitch, R. J., Yatteau, J. H., McElroy, M. B., Gandrud, B. W., Dye, J. E., and Baumgardner, D.: Condensation of $\mathrm{HNO}_{3}$ on falling ice particles: mechanism for denitrification of the polar stratosphere, Geophys. Res. Lett., 17, 449-452, 1990.

Vehkamäki, H., Kulmala, M., Napari, I., Lehtninen, K. E. J., Timmreck, C., Noppel, M., and Laaksonen, A.: An improved parameterization for sulfuric acid-water nucleation rates for tropospheric and stratospheric conditions, J. Geophys. Res., 107, 4622, doi:10.1029/2002JD002184, 2002.

Yin, Y., Carslaw, K. S., and Parker, D. J.: Redistribution of trace gases by convective clouds - mixed-phase processes, Atmos. Chem. Phys., 2, 293-306, 2002. 